\title{
Indicators of regime shifts in ecological systems: what do we need to know and when do we need to know it?
}

\section{Citation}

Contamin, Raphael, and Aaron M. Ellison. 2009. Indicators of regime shifts in ecological systems: what do we need to know and when do we need to know it? Ecological Applications 19(3): 799-816.

\section{Published Version}

http://dx.doi.org/10.1890/08-0109.1

\section{Permanent link}

http://nrs.harvard.edu/urn-3:HUL.InstRepos:2579653

\section{Terms of Use}

This article was downloaded from Harvard University's DASH repository, and is made available under the terms and conditions applicable to Open Access Policy Articles, as set forth at http:// nrs.harvard.edu/urn-3:HUL.InstRepos:dash.current.terms-of-use\#OAP

\section{Share Your Story}

The Harvard community has made this article openly available.

Please share how this access benefits you. Submit a story.

\section{Accessibility}


R. Contamin \& A. M. Ellison - 1 INDICATORS OF REGIME SHIFTS IN ECOLOGICAL SYSTEMS: WHAT DO WE NEED TO KNOW AND WHEN DO WE NEED TO KNOW IT?

and

$8{ }^{1}$ Harvard University, Harvard Forest, 324 North Main Street, Petersham, Massachusetts, 01366,

9 USA

$10{ }^{2}$ Permanent address for RC: ENS Ulm, 45 rue d'Ulm, 75005 Paris, FRANCE

$11 \quad{ }^{3}$ Author for correspondence: aellison@fas.harvard.edu 
R. Contamin \& A. M. Ellison - 2

Abstract. Because novel ecological conditions can cause severe and long-lasting

13 environmental damage with large economic costs, ecologists must identify possible

14 environmental regime shifts and pro-actively guide ecosystem management. As an illustrative

15 example, we apply six potential indicators of impending regime shifts to Carpenter and Brock's

16 (2006) model of lake eutrophication and analyze whether or not they afford adequate advance

17 warning to enable preventative interventions. Our initial analyses suggest that an indicator based

18 on the high-frequency signal in the spectral density of the time-series provides the best advance

19 warning of a regime shift, even when only incomplete information about underlying system

20 drivers and processes is available. In light of this result, we explore two key factors associated

21 with using indicators to prevent regime shifts. The first key factor is the amount of inertia in the

22 system - how fast the system will react to a change in management, given that a manager can

23 actually control relevant system drivers. If rapid, intensive management is possible, our analyses

24 suggest that an indicator must provide at least 20 years advance warning to reduce the

25 probability of a regime shift to $<5 \%$. As time to, or intensity of, intervention is increased, the

26 necessary amount of advance warning required to avoid a regime shift increases exponentially.

27 The second key factor concerns the amount and type of variability intrinsic to the system, and the

28 impact of this variability on the power of an indicator. Indicators are considered powerful if they

29 detect an impending regime shift with adequate lead time for effective management intervention

30 but not so far in advance that interventions are too costly or unnecessary. Intrinsic "noise" in the

31 system obscures the "signal" provided by all indicators and therefore power of the indicators

32 declines rapidly with increasing within- and between-year variability in measurable variables or

33 parameters. Our results highlight the key role of human decisions in managing ecosystems and

34 the importance of pro-active application of the precautionary principle to avoid regime shifts. 
R. Contamin \& A. M. Ellison - 3

Key words: alternative stable states; hysteresis; lakes; management response; regime

36 shift; simulation; spectral density; threshold; time-series.

37

\section{INTRODUCTION}

Ecologists, climatologists, and oceanographers recognize that biological and physical systems can undergo major reorganizations due to changes in underlying environmental conditions. Such "regime shifts" are of significant management concern because many of them have negative ecological impacts (e.g., the shift from oligotrophic to eutrophic states in lakes), whereas others may be deliberately induced to attain specified management goals (e.g., current practices in managing grazing lands or in accelerating ecological restoration). To date, most approaches to identifying regime shifts have been post-hoc - ecologists, climatologists, and statisticians examine historical time-series data of key ecosystem variables to determine whether or not a regime shift has already occurred. But managers - individuals who make decisions about ecosystem management or who implement those decisions - must have indicators that provide reliable advance warning of impending regime shifts. These indicators must provide enough lead time for implementation of management actions so that undesired regime shifts can be forestalled or the system can be moved into the desired regime. Recent research in this area is focused on developing prospective indicators of regime shifts, but these studies have not determined how much advance warning these indicators provide and whether it is enough time to actually direct an ecosystem into the desired regime. Here, we examine in detail how much advance warning six prospective indicators provide. We then explore two issues involved with using these indicators to manage a system subject to a regime shift. The first is what we call the inertia of the system: can progress towards a regime shift be slowed or stopped by a management 
R. Contamin \& A. M. Ellison - 4

58 intervention, or is the system too far gone? The answer depends on the relationship between how

59 far in advance an indicator detects an impending regime shift and how quickly the system can

60 respond to the intervention. Second, all processes are subject to noise - stochastic variance - that

61 can obscure the signal of an impending regime shift. Are certain indicators better at identifying

62 the relevant signal of an impending regime shift? We use shifts from oligotrophic to eutrophic

63 regimes in modeled lakes as our example, but as we discuss at the end of the paper, our results

64 can be generalized to a wide range of ecosystems.

The possibility that ecosystems can exist in alternative stable states was first illustrated using theoretical models (Holling 1973, May 1977). Predictions of these models, in which the

69 parameters defining interactions between species remain constant but either the initial conditions

70 or a strong perturbation to the system lead to alternative equilibrium points (May 1977, Beisner

71 et al. 2003), have been demonstrated in a wide variety of ecosystems (Schröder et al. 2005).

72 Climatologists and oceanographers also have recognized the existence of "regime shifts" -

73 substantial, long-term reorganization of climate systems that result from directional changes in

74 underlying environmental drivers and lead to new temporary or permanent equilibrium states

75 (Easterling and Peterson 1995, Lazante 1996). Directional changes in environmental drivers also

76 can lead to reorganization of ecological systems, and we now recognize regime shifts in a variety

77 of ecosystems, including grasslands and rangelands, coral reefs, oceanic fisheries, and lakes

78 (Steele 1998, Scheffer and Carpenter 2003, Walker and Meyers 2004, Litzow and Ciannelli

79 2007, deYoung et al. 2008). 
R. Contamin \& A. M. Ellison - 5

Regime shifts often are caused by feedbacks among key environmental drivers (e.g.,

81 Carpenter and Brock 2006, Lawrence et al. 2007). Thus, processes that control the system after a

82 regime shift has occurred may not necessarily be the same ones that controlled the system before

83 the regime shift. Consequently, it can be difficult to reverse a regime shift. For example, an

84 increase in the rate of phosphorus $(\mathrm{P})$ recycling from lake sediments back into the water column

85 occurs when the amount of $\mathrm{P}$ in solution reaches a certain threshold, rapidly shifting the lake

86 from an oligotrophic to a eutrophic state (Carpenter and Cottingham 1997). A reduction in the

87 amount of $\mathrm{P}$ after a regime shift may not lead the lake immediately to a shift back into an

88 oligotrophic state (Carpenter et al. 1999) because P recycling no longer uniquely controls the

89 new state of the system. Similarly, in rangeland systems, when shrub cover is low, grasslands

90 can recover from overgrazing when grazers are removed. But when shrub cover is higher,

91 grasslands cannot recover from overgrazing after grazers are removed because shrubs

92 outcompete grasses (Anderies et al. 2002, Bestelmeyer et al. 2006). Transitions between

93 grassland and shrubland states can be further controlled by frequency of fire, but the relative

94 impact of competition (bottom-up effects) and grazing/predation (top-down effects) differ

95 strongly in the different states (Anderies et al. 2002, Bestelmeyer et al. 2006).

96 Climatologists, oceanographers, and statisticians have focused on post-hoc identification

97 of regime shifts in long time-series (Easterling and Peterson 1995, Lazante 1996, Solow and Beet

98 2005, Rodionov 2005a, 2005b), but such methods are of little use if a management goal is to

99 avoid (or accelerate) a regime shift. Recent work with models of lake ecosystems suggests that

100 increased variance of an evolving time-series may presage a regime shift from an oligotrophic to

101 a eutrophic state (Brock and Carpenter 2006, Carpenter and Brock 2006). Indicators of regime

102 shifts in atmospheric and oceanic (both physical and biological systems) include a change in the 
R. Contamin \& A. M. Ellison - 6

103 variance spectrum towards lower frequencies (Rodionov 2005c). van Nes and Scheffer (2007)

104 identified a decreased rate of recovery from small perturbations as an indicator for regime shifts

105 in models of aquatic macrophyte population dynamics; asymmetric competition between two or

106 more species; effects of grazing pressure on populations; and phosphorus cycling in lakes. The

107 development and use of any indicator should allow managers to anticipate regime shifts and

108 manage systems accordingly, but it is not clear whether available indicators provide sufficient

109 advance warning to managers who are working with relatively short time-series and incomplete

110 information about the system of interest.

111 Our approach here is to explore potential methods to detect regime shifts when only

112 partial knowledge of important underlying ecological processes is available, and then to use

113 these methods to suggest conservative management strategies. We address these questions by

114 applying several different indicators of an impending regime shift to an example system:

115 Carpenter and Brock's (2006) model of lake eutrophication. We use this model because it has

116 been used extensively to explore the possibility of detecting regime shifts (Brock and Carpenter

117 2006, Carpenter and Brock 2006).

118 Our approach differs from previously published economic and ecological approaches to

119 detecting and managing regime shifts. Economists have tended to focus on the value of an

120 ecosystem and have used cost-benefit analysis to determine the cost of a regime shift (for

121 application of these economic models to ecological systems see Carpenter et al. 1999, Ludwig et

122 al. 2003, Ludwig et al. 2005). Such a cost-benefit analysis results in a utility function for the

123 ecosystem that depends on the state of the system and any additional inputs. Deterministic

124 models are employed to determine the utility function that maximizes the economic value of the

125 ecosystem. It is important to note that such an analysis expects managers to have a deterministic 
R. Contamin \& A. M. Ellison - 7

126 ecosystem model that describes the true dynamics of the system and allows for accurate forecasts

127 of future states, including regime shifts. Such models are rarely available.

128 In contrast, ecological approaches have focused attention on detecting regime shifts

129 given available data (Carpenter 2003, Keller et al. 2005). Recent approaches assume imperfect

130 knowledge about the system and instead use simple models that approximate system dynamics

131 (e.g., Carpenter and Brock 2006). These dynamic time-series models continually update

132 parameter estimates as more knowledge accrues. Unfortunately, in models developed to date,

133 parameter estimates become most reliable only after the threshold to a new regime has been

134 crossed (Carpenter 2003).

135 The structure of this paper is as follows. First, we present a précis of Carpenter and

136 Brock's (2006) lake model and the minor modifications that we made to it. Within this section,

137 we also describe the different sources of stochasticity that contribute to variability in the model

138 output. Second, we describe six indicators for impending regime shifts. Third, we illustrate the

139 inertia of this system and discuss how far in advance an indicator must signal a regime shift for a

140 management intervention to be effective. Fourth, we explore how differences in the types and

141 magnitudes of variability in the system influence the power of each of the indicators and their

142 ability to detect a regime shift. Finally, we discuss how managers could actually use these

143 indicators to develop and implement realistic management plans.

144

THE LAKE MODEL

The basic model

Carpenter has developed a detailed model of ecosystem dynamics of lakes subject to

148 phosphorus (P) input from non-point-source agricultural inputs (Carpenter 2003, Carpenter and 
R. Contamin \& A. M. Ellison - 8

149 Brock 2006). Such chronic, long-term stressors are common features of many ecosystems,

150 including forests subject to atmospheric deposition of nitrogen, sulfur, and heavy metals (e.g.,

151 Gbondo-Tugbawa et al., 2002, Holland et al. 2005, Vanarsdale et al. 2005) and estuaries and

152 coastal waters that receive run-off from large rivers (e.g., Rabalais et al. 2002). We focus here on

153 a lake model because many underlying processes driving lake ecosystem dynamics are well

154 understood (Carpenter 2003) and because indicators of regime shifts have been developed using

155 lake models (Carpenter and Brock 2006, van Nes and Scheffer 2007).

156 But ecosystems are not impacted only by chronic, non-point-source stressors. Point-

157 sources of pollutants (which may affect ecosystems acutely through single or intermittent

158 discharges, or chronically through continuous operations of, e.g., smelters or power plants) or

159 targeted harvesting or grazing operations are examples of stressors for which continued operation

160 could cause regime shifts but which are more tractably managed. Pipes can be shut off, herds can

161 be moved, or fishing boats can be beached more readily than diffuse plumes of nitrogen moving

162 through soil can be contained. Therefore, we modified Carpenter and Brock's (2006) model of

163 lake ecosystems to include both types of stressors - non-point-source (i.e., leaching of P from

164 soil into water, as in the original model) and point-sources (i.e., direct discharge into the water of

$165 \mathrm{P}$ as industrial effluent) (Fig. 1). This addition allows our results to be generalized beyond

166 agricultural systems.

167 The model we use is a system of three coupled stochastic differential equations for the

168 density $\left(\mathrm{g} / \mathrm{m}^{2}\right)$ of $\mathrm{P}$ in soil $(U)$, lake water $(X)$ and lake sediments $(M)$ :

$$
\frac{d U}{d t}=F_{a}-c U H
$$


R. Contamin \& A. M. Ellison - 9

$$
\begin{gathered}
\frac{d X}{d t}=F_{i}+c U H\left(1+\varepsilon \frac{d W_{1}}{d t}\right)-(s+h) X+M R(X)\left(r+\sigma \frac{d W_{2}}{d t}\right) \\
\frac{d M}{d t}=s X-b M-M R(X)\left(r+\sigma \frac{d W_{2}}{d t}\right) .
\end{gathered}
$$

173 The meaning and units of each variable and parameter in this model are given in Table 1.

The model is solved for successive summer seasons when the lake is stratified. The time-

175 steps are one year (annual) for changes in $U$ (phosphorus in soil) and 36 within-year increments

176 for $X$ (phosphorus in water) and $M$ (phosphorus in lake sediments). The different time scales at

177 which each of these processes occur are based both on current understanding of lake ecosystems

178 and on consistency with Carpenter's coding of the model (personal communication from Steve

179 Carpenter, May 2007). We followed Carpenter and Brock (2006) in assuming that the nutrients

180 from the soil enter into the system once each year, prior to summer stratification of the lake.

181 Equation 1 is solved on annual time steps, and this annual input is then distributed over all the

182 within-year time-steps used to solve Eqns. 2 and 3. In contrast, recycling occurs continually

183 throughout the year due to stochastic events driven by wind (Sorrano et al. 1997).

184 In Eqn. 1, $F_{a}$ is the input rate of $\mathrm{P}$ to soil (from fertilizer use, dust deposition, or

185 weathering). Equation 2 calculates the annual input of $\mathrm{P}$ into water, which comes from two

186 primary sources. First is the non-point source leakage of $\mathrm{P}$ from soil into water, which is the

187 product of soil $\mathrm{P}(U)$, the transfer coefficient from the soil into the lake (c), and two sources of

188 variability, $H$, and $\varepsilon \frac{d W_{1}}{d t}$ (see Sources of variability in the model, below); throughout, we refer

189 to the product $c U H\left(1+\varepsilon \frac{d W_{1}}{d t}\right)$ as $F_{\text {soil }}$. Second are the additional inputs of $\mathrm{P}$ from industrial 
R. Contamin \& A. M. Ellison - 10

190 sources $\left(F_{i}\right)$. Throughout, we refer to total $\mathrm{P}$ inputs, the sum of $F_{i}$ and $F_{\text {soil, }}$ as $F_{\text {total. }}$ Loss of $\mathrm{P}$

191 from the water column occurs through sedimentation $(s)$ and outflow (h). Equation 3 determines

192 the amount of $\mathrm{P}$ in lake sediments as a function of sedimentation (s) and burial (b), and a

193 recycling coefficient $r$. Recycling of $\mathrm{P}$ from sediment back into the water column acts as a third

194 source of $\mathrm{P}$ input to the system and it is increases in P recycling that trigger the regime shift in

195 the lake model (Carpenter 2003, Carpenter and Brock 2006). This recycling of $\mathrm{P}$ is represented

196 by the recycling function $R(X)$ :

$$
R(X)=\frac{X^{q}}{m^{q}+X^{q}}
$$

198 where $m$ is the value $\left(2.4 \mathrm{~g} / \mathrm{m}^{2}\right)$ at which recycling is half the maximum rate and the exponent $q$ 199 determines the slope of $R(X)$ near $m$ (Carpenter et al. 1999). $R(X)$ ranges from 0 to 1 , and $R(m)=$ $200 \quad 0.5$.

201 In our initial simulations and numerical analyses, we used values for all the parameters 202 estimated for Lake Mendota, Wisconsin, as provided in Table S1 of Carpenter and Brock (2006)

203 (see also our Table 1). To determine how each of these parameters affects the behavior of

204 different indicators of regime shifts, we suppressed or changed the values of one or more sources 205 of variability in some of the simulations described below (by setting one or all of $\lambda$, $\varepsilon$, or $\sigma$ equal 206 to zero or to a value lower value than the defaults: see Table 1). All simulations and analysis

207 were done using the $\mathrm{R}$ language ( $\mathrm{R}$ Development Core Team 2007), version 2.4.

208 Figure 2 illustrates the behavior of this model subject to realistic increases in inputs of the 209 two different sources of P. For both sources, we started the simulations at oligotrophic 210 equilibrium, and with $F_{a}=0.3$. In the first case we fixed $F_{a}$ at $0.3 \mathrm{~g} / \mathrm{m}^{2}$ but increased $F_{i}$ from 0 to $2111.2 \mathrm{~g} / \mathrm{m}^{2}$ (Fig. 2A), which resulted in a total input of phosphorus (point-source + non-point 
R. Contamin \& A. M. Ellison - 11

212 source) of $1.5 \mathrm{~g} / \mathrm{m}^{2}$ by year 300 (Fig. 2B). In the second case we fixed $F_{i}$ at 0 and we increased

213 agricultural inputs $F_{a}$ from 0.3 to $10 \mathrm{~g} / \mathrm{m}^{2}$ (Fig. $2 \mathrm{~A}$ ), which also led to an increase in $F_{\text {total }}\left(=F_{\text {soil }}\right.$

214 alone in this case) of $1.5 \mathrm{~g} / \mathrm{m}^{2}$ by year 300 (Fig. 2C). At these levels of total P inputs, the lake

215 model shifted from an oligotrophic to a eutrophic state (i.e., a regime shift occurred) sometime

216 between simulated years 225 and 275 (dark grey vertical lines in Figs 2D and 2E). In both cases

217 we dropped $F_{i}$ or $F_{a}$ to zero at year 300, shortly after the regime shift occurred.

218 As point-source input $\left(F_{i}\right)$ increased (Fig. 2A), the total $\mathrm{P}$ in the water increased slowly at

219 first and then the lake abruptly shifted to a eutrophic state (Fig. 2D). Turning off the point-source

220 input resulted in a relatively rapid return to oligotrophic conditions (Fig. 2D). In contrast, a

221 similar pattern of increase and then abrupt decrease in non-point source inputs of P to soil $\left(F_{a}\right.$;

222 Fig. 2A) was not paralleled by an abrupt decrease in total P inputs (Fig. 2C) because of the slow

223 rate of transfer of $\mathrm{P}$ from soil to water. The shift from an oligotrophic regime to a eutrophic one

224 was relatively rapid, but the time to reversal was lengthy (Fig. 2E) and controlled in part by the

225 parameter $c$, the transfer coefficient of $\mathrm{P}$ from the soil into the lake. In both cases the new state of

226 the lake system showed some resilience, as the regime shift was not reversed immediately.

227 However, it took much more time to reverse a regime shift caused by non-point-source

228 agricultural inputs $F_{a}$ because the soil acted as a "sponge" and continued to release $\mathrm{P}$ to the lake

229 long after inputs have stopped.

Sources of variability in the model 
R. Contamin \& A. M. Ellison - 12

$$
H=\exp \left(Z-\frac{\lambda^{2}}{2}\right)
$$

235 where $Z$ is a white noise process with mean $=0$ and variance $=\lambda^{2} . H$ generates a random

236 lognormal variable with mean $=1$. Second, there is within-year variation that depends on $\varepsilon$ in

237 Eqn. $2\left(d W_{1}\right.$ is a white noise process with mean $=0$ and variance $\left.=d t\right)$. Such variation could be

238 caused by irregular rainfall events, for example. Third, frequent shocks to recycling because of

239 wind events within the summer season are represented by $\sigma M R(X) \frac{d W_{2}}{d t}$ in Eqns. 2 and 3; $d W_{2}$

240 also is a white noise process with mean $=0$ and variance $=d t$. Note that $Z$ is independent of $d W_{1}$,

241 and $d W_{2}$. These three sources of variability are illustrated schematically in Figure 3, which shows

242 that the control parameters $\varepsilon$ and $\sigma$ have similar effects on within-year variability in

243 concentration of phosphorus in the water column.

244 The key to understanding how a regime shift can occur in this system is to recognize

245 processes occurring on three time scales (Brock and Carpenter 2006). The first is a very slow

246 change in an exogenous driver or in a slowly changing system component, such as $F_{a}$ or $F_{i}$ in

247 Equations 1 and 2 (see also Fig. 2). The second is a medium-speed change in the state variable

248 subject to the regime shift, such as the concentration of $\mathrm{P}$ in the water column $(X)$. The third is a

249 fast change in $X$ due to the white-noise processes $Z, d W_{1}$, or $d W_{2}$ (Table 1; Fig. 3).

250 Since the value of $F_{\text {soil }}$ depends on $\lambda$ and $\varepsilon$, the annual variance in $X$ increases with inputs

251 of phosphorus from soil. The parameter $\sigma$ begins to affect the system once P recycling from the

252 sediment into the water column begins. Therefore, if a regime shift is caused by an increase in

253 agricultural inputs, an increase in the variance of $X$ should precede a regime shift (Carpenter and

254 Brock 2006). The parameter $\lambda$ controls annual (between-year) variance, so ideally we would like 
R. Contamin \& A. M. Ellison - 13

255 to identify indicators that can differentiate within-year variance (e.g., variance due to the control

256 parameters $\varepsilon$ and $\sigma$ ) from between-year variance due to $\lambda$. Such indicators also should allow us

257 to detect the "signal" of an impending regime shift from the background "noise" of normal

258 within-year and between-year variance.

\section{INDICATORS OF REGIME SHIFTS}

The lake model (Eqns. 1-3) is the result of decades of study and a deep understanding of

262 lake biogeochemistry (Carpenter 2003). However, few ecosystems are as well understood, and

263 most often we do not have a mechanistic understanding, let alone measurements, of all the

264 underlying drivers determining an ecosystem's state. Rather, we are more likely to work with a

265 simplified model of the system (Carpenter and Brock 2006). In monitoring lakes, we typically

266 monitor inputs of $\mathrm{P}$ from industry $\left(F_{i}\right)$ or soil $\left(F_{\text {soil }}\right)$ annually or at regular within-year intervals.

267 Annual concentration of $\mathrm{P}$ in the water $(X)$ is estimated from samples taken throughout the year.

268 From these observations, we can estimate change in water $\mathrm{P}$ as:

$$
\frac{d X}{d t}=a_{0}+\left(F_{i}+F_{\text {soil }}\right)-a_{1} X
$$

270 where $a_{0}$ and $a_{1}$ are parameters that represent the true but unknown processes for recycling of $\mathrm{P}$

271 from the sediment into the water column $\left(a_{0}\right)$ and losses of $\mathrm{P}$ from the system $\left(a_{1}\right)$. Total $\mathrm{P}$ input $272\left(F_{i}+F_{\text {soil }}=F_{\text {total }}\right)$ is assumed constant during the course of a year. This model is a dynamic linear

273 model (DLM; Pole et al. 1994) that is upgraded annually (Brock and Carpenter 2006):

274

$$
X_{[\mathrm{DLM}], t}=X_{t-1} \exp \left(-a_{1_{t-1}}\right)+\frac{1+\exp \left(-a_{1_{t-1}}\right)}{a_{1_{t-1}}}+\left(F_{i}+F_{\text {soil }}\right)+\frac{a_{0_{t-1}}\left(1-\exp \left(-a_{1_{t-1}}\right)\right)}{a_{1_{t-1}}}(7)
$$


R. Contamin \& A. M. Ellison - 14

275 Using this model and the observed time series of $F_{\text {total }}$ and $X$, one important goal is to develop

276 clear indicators that will suggest a regime shift with ample time to respond. We explore the

277 behavior of six such indicators (Table 2). Other indicators have been proposed but cannot be

278 easily used in a management context. For example, indicators of resilience suggested by van Nes

279 and Scheffer (2007) require experimental interventions, and an indicator based on Fisher

280 Information is applicable only to systems that exhibit periodic time-series (Fath et al. 2003).

281 Brock and Carpenter (2006) showed that the maximum eigenvalue of the variance-covariance

282 matrix of their modeled system increases steeply prior to a regime shift. We also saw this

283 behavior in our analysis of the lake model, but in order to use this indicator, a manager would

284 need to have reliable within-year data on concentrations of P in sediments ( $M$ in Equations 2 and

285 3). Such data are rarely available in lake monitoring programs. Rodionov (2005a, 2005c)

286 summarizes a number of other indicators used by climatologists that require amounts of data that

287 are rarely available to ecologists or environmental managers.

The six indicators we used are listed in Table 2. The first two, $\mathrm{SD}$ and $\mathrm{SD}_{\mathrm{DLM}}$, are the

289 standard deviation of the within-year values of $\mathrm{P}$ in the water column $(X)$ around the mean of the

290 model output (Eqn. 2) or around the prediction of the DLM (Eqn. 7), respectively (Carpenter and

291 Brock 2006). Carpenter and Brock (2006) showed that because recycling of P from sediments to

292 water increases before a regime shift, so does variability in the system due to $\sigma$ (Fig. 3E, 3F), and

293 so do $\mathrm{SD}$ and $\mathrm{SD}_{\mathrm{DLM}}$. $\mathrm{SD}_{\mathrm{DLM}}$ also may be less susceptible to changes in between-year variability $294(\lambda)$.

295 The third indicator, $\mathrm{SD}_{\text {rec }}$, is based on the fact that there is a predictably large shock to the 296 system (excess P input) at the beginning of each year due to $\lambda$. Part of the within-year variation

297 is caused by an adjustment of the system to this shock; if we assume that this adjustment is 
R. Contamin \& A. M. Ellison - 15

298 linear, linearize the within-year values of $X$, and then take the standard deviation around this

299 linear model, we may be able to detect the signal due to the onset of recycling of $\mathrm{P}$ from

300 sediments to the water column more clearly. In the equation for $\mathrm{SD}_{\text {rec }}, X_{[\mathrm{rec}], t}$ is the vector of

301 linear fitted values for each year $t . X_{[\mathrm{rec}], t}$ is calculated using the $1 \mathrm{~m}$ function in R to estimate $X$

302 (the 36 within-year values of water-column P) as a function of time.

303 The SPEC indicator is based on the idea that within-year spikes (sharp increases followed

304 by sharp decreases in a measured variable) in water-column P caused by recycling will, for some

305 frequencies, result in an increase in spectral density of the time-series. That is, if there is no

306 within-year variance in $X$, or if $X$ increases or decreases smoothly within a given year, there will

307 be no high-frequency signal to its time-series. However, when there are many spikes in $X$ within

308 a given year, a high-frequency periodic signal in the time-series may be detectable. Using the 36

309 within-year $X$ values generated by the model, we estimated the maximum spectral density using

310 the R function spec (in package stats). This may seem like a very approximate indicator, but

311 like the other indicators, SPEC can be upgraded annually. It is also similar to other indicators

312 predicated on the idea that new processes and regimes may change the variance spectrum of

313 underlying time-series (Kleinen et al. 2003). Furthermore, the only assumption of this indicator

314 is that recycling of $\mathrm{P}$ from sediments back into the water column occurs in bursts during the

315 summer season; no additional data are required by a manager to determine the value of SPEC.

316 The $a_{0}$ indicator is simply based on the updated parameters in the DLM (Equations 6 and

317 7). When phosphorus recycling starts, there is a change in the processes that the DLM might be

318 able to detect. Finally, $X$ itself could be used as an indicator, because recycling causes spikes in

319 the time-series of values of water-column P. We use this last indicator, $X$, as a "control" to see if

320 the other indicators really improve the detection of regime shifts. 
R. Contamin \& A. M. Ellison - 16

As $\mathrm{P}$ input increases, total water P (Fig. 4, top row) and all of the indicators (Fig. 4, rows

322 2-6) increase in value and variance after recycling of $\mathrm{P}$ from sediments to the water column starts

323 (vertical grey lines in Fig. 4) but before the regime shift occurs at time $\sim 245$ in these

324 simulations. The "signal" of the indicator is clearest when the only variability in the system is

325 due to $\sigma$ (Fig. 4, left column). As additional sources of variability are added, it is substantially

326 more difficult to detect a "signal" within the annual variability of the indicators. Clearly, the

327 variance in each indicator increases after recycling starts (Fig. 4, right column).

HOW SOON MUST A REGIME SHIFT BE DETECTED IN ORDER TO PREVENT IT?

\section{Methods}

Our first analysis asks if progress of a system towards a regime shift is irreversible (at

332 least in the short term) or if it can be slowed or stopped (or accelerated) by a management

333 intervention. The critical piece of information is the relationship between the lead time an

334 indicator provides before a regime shift occurs and how quickly the system can respond to an

335 intervention. As illustrated in the description of the model, the rate of response also may depend

336 on the input source, here non-point source leakage of $\mathrm{P}$ from soil $\left(F_{\text {soil }}\right)$ and point-source inputs

337 of $\mathrm{P}\left(F_{i}\right)$ (Fig. 2, above).

338 To identify how far in advance any indicator must detect a regime shift so that a

339 management intervention can successfully avert it, we used the same input schedules of P into

340 soil $\left(F_{a}\right)$ and directly into water $\left(F_{i}\right)$ as we used to generate Fig. 2, above (parameters given in

341 Table 1). We noted in the output when different levels of $\mathrm{P}$ were recycled from the lake

342 sediments $(R(X)=0.0001,0.001,0.01$, and 0.1$)$, and when the shift from an oligotrophic to a

343 eutrophic regime occurred. We then altered the values of $F_{a}$ and $F_{i}$ (i.e, simulated a management 
R. Contamin \& A. M. Ellison - 17

344 response), and re-ran the simulation beginning at the year of the regime shift, and for each year

345 preceding the regime shift. The number of years back that we restarted the system is called the

346 Delay. It represents the (simulated) time an indicator gives a manager to attempt to prevent a

347 regime shift.

348 Management responses depend on three parameters: (1) Resp - the number of years

349 before any intervention (this represents, for example, the time it takes a manager to convince

350 industry to stop P inputs into the lake); (2) Base level - the fraction of total (P) inputs that the

351 manager cannot eliminate; and (3) Nyears - the number of years it takes to reach Base level. We

352 simulated three different management responses. The first is a slow response that allows for high

353 base level of P inputs: Resp $=10$, Base level $=0.5$, Nyears $=50$. The second is an intermediate

354 response that allows for a lower base level of $\mathrm{P}$ inputs: $\operatorname{Res} p=5$, Base level $=0.1$, Nyears $=10$.

355 The third is a fast response that allows for no base level of $\mathrm{P}$ inputs: Resp $=0$, Base level $=0.0$,

356 Nyears $=2$. With these responses, we re-ran the simulations for 500 years for a range of Delay

357 values. We determined whether a regime shift would still occur, and if it did, how long it would

358 take to return the lake to the oligotrophic state following the different management interventions.

359 We considered a regime shift to have occurred when the mean value of $\mathrm{P}$ in the water column

360 exceeded $2.4 \mathrm{~g} / \mathrm{m}^{2}$, the concentration at which the rate of recycling $R(X)$ is 0.5 (i.e., $X=m=2.4$

$361 \mathrm{~g} / \mathrm{m}^{2}$ ). We ran 200 replicate runs for each set of parameters: P input schedules (temporal

362 trajectories of $F_{a}$ and $F_{i}$, and the three management responses.

\section{Results}

365 If the increase in $\mathrm{P}$ input was entirely due to point-source effluent $\left(F_{i}\right)$, the worst-case 
R. Contamin \& A. M. Ellison - 18

367 a regime shift if it was applied 30 years in advance (Fig 5A). In contrast, for non-point source

368 inputs $\left(F_{a}, F_{\text {soil }}\right)$, the best-case management intervention (rapid response, no allowable base-level

369 of inputs) needed to have been applied at least 35 years in advance, and the worst-case

370 intervention needed to have been applied at least 70 years in advance, to prevent the lake from

371 shifting into a eutrophic state (Fig. 5B). For agricultural inputs, recycling of $\mathrm{P}$ from lake

372 sediments to the water column reached $0.001(0.1 \%) 60$ years before the regime shift, and 0.01

373 (1\%) 22 years before the regime shift was observed (Fig. 5B). Extrapolating this result to the

374 "real world", where best-case interventions are unlikely, any indicator of a regime shift must

375 detect a small recycling rate many decades in advance if regime shifts are to be avoided.

376 However, even if a regime shift cannot be prevented, intervention still may have utility.

377 The mean recovery time of the system - how long it takes for the model system to return to an

378 oligotrophic regime - is shorter when management intervention is applied sooner (Figs. 5C, 5D).

379 This conclusion applies not only to lake eutrophication. The use of indicators for detection of

380 regime shifts and triggering of management interventions will be most successful when a

381 manager can quickly change a control variable (i.e., small management inertia) and when there

382 are no processes that will otherwise slow the response of the system; here, accumulation of $\mathrm{P}$ in

383 the soil and its subsequent slow release (i.e., small system inertia). Our analyses also assume a

384 fixed linear schedule of change for $F_{i}$ and $F_{a}$; that managers can measure and control these

385 important input variables; and that their decisions to intervene depend strictly on preventing a

386 regime shift. Variation in rates of change of inputs, the starting point of the system, stochastic

387 noise, and constraints on decision-making all can influence the success of a monitoring or

388 management plan. We discuss these in more detail in the last section of the paper, after we

389 discuss the power of different types of indicators in the face of stochasticity in the system. 
R. Contamin \& A. M. Ellison - 19

HOW POWERFUL ARE THE INDICATORS AT DETECTING IMPENDING REGIME SHIFTS?

\section{Methods}

When $\mathrm{P}$ begins to recycle from the sediments back into the water column, spikes of $\mathrm{P}$ in

394 the water column become measurable. Thus, we hypothesized that by comparing the magnitude

395 of spikes in water column P before and after P recycling had begun $(R(X)=0.0001)$, we could

396 determine how powerful each of the indicators is at detecting a regime shift with different levels

397 of variability from each of the three possible sources $(\lambda, \mathcal{E}$, and $\sigma)$. An indicator is considered to

398 be powerful if it detects an impending regime shift with sufficient lead time to allow for an

399 effective management intervention, but not so far in advance that an intervention is not cost-

400 effective. In particular, we suggest that if an indicator is powerful at identifying a regime shift,

401 the spikes that occur in its time-series once P recycling starts and a regime shift is imminent

402 should be much larger than the spikes that occurred earlier in the time series. Ideally, an indicator

403 should pick up the potential for a regime shift far enough in advance for a management

404 intervention to avoid (or minimize the probability of) a regime shift.

405 As before, we generated time-series of the lake system beginning at oligotrophic

406 equilibrium and applied the same inputs of $F_{i}$ and $F_{a}$. When $F_{a}$ was held constant while $F_{i}$

407 increased, only within-year recycling variability (controlled by $\sigma$ ) increased. In contrast, when $F_{a}$

408 increased, between-year and within-year variability (controlled by $\lambda$ and $\varepsilon$ ) also increased, and

409 within-year recycling variability (controlled by $\sigma$ ) only increased after recycling started. For

410 each input schedule, we varied $\lambda, \varepsilon$, and $\sigma$ (Table 3), and for each combination, we ran 500

411 replicate simulations. For each input schedule of $\mathrm{P}$ and the combinations of variance parameters 
R. Contamin \& A. M. Ellison - 20

412 given in Table 3, we ask: (1) which indicator gives the best results with for the given set of

413 parameters; (2) which indicator best detects the onset of recycling of $P$ from the sediment back

414 into the water column; and (3) which indicator is best able to isolate variability due to $\mathrm{P}$

415 recycling from the other sources of variability.

416 First, to determine the power of each indicator as a function of time-to-regime shift

417 (=Delay), we constructed the vector of the difference between adjacent values in the indicator

418 time series (the value at time $t+1$ minus the value at time $t$ ), running from the onset of $\mathrm{P}$

419 recycling $(R(X)=0.0001)$ to the time-of-intervention Delay (Delay $\leq$ Year $_{R S}$, the year in which

420 the regime shift occurred). We called this vector $\mathrm{SPIKE}_{1}$ and it contains the differences between

421 adjacent indicator values; the maximum value of $\operatorname{SPIKE}_{1}$ represents the highest spike in the

422 indicator time-series. We then constructed a similar vector (called $\left.\mathrm{SPIKE}_{2}\right)$ in the time-series of

423 identical length running backwards from the onset of $\mathrm{P}$ recycling. Our measure of power is the

$424 \log$ of the ratio of the maximum values of each of the two vectors:

$$
\log \left(\frac{\max \left(\text { Spike }_{1}\right)}{\max \left(\text { Spike }_{2}\right)},\right.
$$

427 which basically represents how much higher the spikes in the indicator time series are after the

428 onset of $\mathrm{P}$ recycling. If the magnitudes of the spikes are equivalent before and after the onset of 429 recycling, Equation $8=0$ and the indicator does not detect the upcoming regime shift (i.e., its

430 power is low). We compared the powers of the different indicators for each set of variance 431 parameters in Table 3 by plotting the power (Eqn. 8) vs. Delay, and estimating the area under 432 each curve using the R function diffinv in package stats. Higher values of power suggest 
R. Contamin \& A. M. Ellison - 21

433 that the indicator is able to discriminate the signal from the noise for each combination of

434 parameters.

435 Second, as spikes in the time-series of concentration of $\mathrm{P}$ in the water column are much

436 larger after P-recycling has started, we wanted to isolate those spikes that were "large enough" to

437 correctly identify a regime shift. We use the algorithm in Box 1 to determine whether an

438 indicator detects a regime shift. This approach is much closer to a year-to-year management

439 approach than annual computation of the log of the ratio of the two vectors of spikes (Eqn. 8).

Box 1. Algorithm to determine whether an indicator detects a regime shift.

1. Record the values of the first twenty spikes in the time-series, and store in vector SPIKE.

2. For each subsequent year, determine if another spike occurs in the time-series.

3. If there is a spike, compare its value with SPIKE using different "filters". The filter uses the mean and standard deviation of the SPIKE to create a limit value:

$$
\text { LimitValue }=\operatorname{mean}(\text { SPIKE })+\text { FAC } \times \operatorname{SD}(\text { SPIKE })
$$

where FAC is a coefficient that determines the sensitivity of the indicator.

4. If the spike of the year is above LimitValue, then the indicator detects a regime shift. Else, upgrade SPIKE (by using the new spike and the preceding 19 to create a new vector SPIKE) and return to step 2.

452 increments of 0.5 ) to construct different filters. When the indicator detected a regime shift, we 453 compared the year of detection $\left(\right.$ Year $\left._{D}\right)$ with the year at which recycling of $\mathrm{P}$ from sediment to 454 the water column actually began in the simulations $\left(\right.$ Year $\left._{R E C}\right)$ and with the year at which the 
R. Contamin \& A. M. Ellison - 22

455 regime shift actually occurred in the simulations $\left(\right.$ Year $\left._{R S}\right)$ (note that Delay $=$ Year $_{R S}-$ Year $_{D}$, and

456 is the time an indicator provides that can be used to prevent a regime shift from occurring).

457 We define two different types of error: $\alpha=$ the fraction of runs in which Year $_{D}>$ Year $_{R S}-$

458 Delay, and is the proportion of runs in which the detection occurs too late for an intervention to

459 prevent a regime shift. In contrast, $\beta=$ the fraction of runs in which $\operatorname{Year}_{D}<\mathrm{Year}_{R E C}$, and is the

460 proportion of runs that detected a regime shift too early, suggesting an intervention before it is

461 needed to stop the regime shift. The remainder $(1-[\alpha+\beta])$ is the fraction of runs that provide

462 good detection of impending regime shifts $\left(\operatorname{Year}_{R E C} \leq \operatorname{Year}_{D}<\operatorname{Year}_{R S}-\right.$ Delay$)$. Good detection

463 implies adequate time to prevent a regime shift in a cost-effective manner.

464 We define the overall error rate as

465

$$
\text { Error }=\operatorname{percent}(\beta)+[5 \times \operatorname{percent}(\alpha)]
$$

466 This error rate weights $\alpha$ more than $\beta$ because errors in $\alpha$ are false negatives, whereas errors in $\beta$

467 are false positives. In this case, a false negative has more serious management consequences than

468 a false positive. We used an arbitrary weighting factor of 5, but other weights could be used

469 without qualitatively changing the results. By comparing values of Error as a function of Delay

470 for each indicator and each filter, we can identify "optimal” filters and error values for each

471 indicator across a range of parameters affecting variability in the system.

Results

474 When only $F_{a}$ increased and when variance parameters were set at high levels (set

475 number 6 in Table 3), all the indicators had higher power when the regime shift was imminent 476 (Delay $\rightarrow$ 0; Fig. 6). Power for all indicators approached 0 as Delay increased, but even when 
R. Contamin \& A. M. Ellison - 23

477 Delay $=30, \mathrm{SD}_{\text {rec }}$ and SPEC detected the upcoming regime shift (Fig. 6). For this combination of

478 inputs and variability, $\mathrm{SD}$ and $\mathrm{SD}_{\mathrm{DLM}}$ provided little gain in power relative to the time-series

479 itself $(X)$, and $a_{0}$ provided no indication of an impending regime shift at all (Fig. 6).

480 As we altered combinations of values of the variance parameters (Table 3), the rank order

481 of the power of each indicator did not change, but the total power did (Fig. 7). With very low

482 values for the parameters (Table 3, set 1), all indicators were poor (black bars in Fig. 7).

483 Increasing the value of $\sigma$ (variability in recycling) alone improved the power of all the indicators

484 (dark grey bars in Fig. 7), but SPEC worked better, and $X$ worked more poorly, than all the other

485 indicators. The power of all the indicators decreased as the other variance parameters were

486 increased (lighter grey and white bars in Fig. 7). Two indicators, $\mathrm{SD}_{\mathrm{rec}}$ and $\mathrm{SPEC}$ were less

487 responsive to increasing $\lambda$ than the other indicators (Fig. 7), because between-year variance did

488 not affect within-year patterns and did not alter the power of SPEC, which measures within-year

489 spectral density. Since we purposely designed $\mathrm{SD}_{\text {rec }}$ not to respond to the shock at the beginning

490 of each year, its lack of response to changes in $\lambda$ was not surprising. The power of the other

491 indicators declined as $\lambda$ increased (Fig. 7). None of the indicators were particularly resistant to

492 changes in $\varepsilon$, which is difficult to distinguish from variability due to $\sigma$ (Fig. 3).

493 When $F_{a}$ was held constant and increases in $F_{\text {total }}$ were due entirely to $F_{i}$, the conclusions

494 were qualitatively similar (data not shown). Overall power of all the indicators were better when

$495 \quad F_{i}$ was the primary input source because $F_{a}$ was lower and so there was less variability in the

496 system due to $\varepsilon$ and $\lambda$. Comparing the two different types of inputs, we note that if two different

497 input sources can trigger a regime shift (e.g., $F_{a}$ and $\left.F_{i}\right)$, then detection of an upcoming regime 
R. Contamin \& A. M. Ellison - 24

498 shift will be more difficult if the input source (here $F_{a}$ ) that contributes most to the underlying

499 variability is also the one that is increasing.

500 All indicators had lower values of total error (Eqn. 10) when a regime shift was imminent

501 (low values of Delay), and errors increased with time to the regime shift (Fig. 8). The error rates

502 paralleled the power of the indicators. SPEC and $\mathrm{SD}_{\text {rec }}$ had the lowest error values whereas $a_{0}$ and

$503 X$ had the highest error values. With increasing non-point-source inputs $\left(F_{a}\right.$ increasing, $\left.F_{i}=0\right)$

504 and with realistic values for the variance parameters, $\mathrm{SD}_{\text {rec }}$ and SPEC could detect regime shifts

505 with relatively low error $(<30 \%)$ up to 5 simulated years in advance (Fig. 8A). Alternatively, if

506 non-point-source inputs are held constant and point-source inputs are increasing, these two

507 indicators could reliably detect regime shifts up to 40 simulated years in advance (Fig. 8B).

508 The results that we show here used the FAC value that minimizes the error rate for each

509 indicator. In a real management case, choosing the FAC value to use depends on the management

510 goals: if a manager wants warning of a regime shift far in advance, the algorithm should be more

511 sensitive, so FAC should be set relatively low. Because the examination of both the power and

512 the detection ability (error rate) of the different indicators yielded similar conclusions, the

513 detection algorithm (Box 1) could be used in a monitoring program to detect a regime shift for a

514 given value of FAC. Thus, in the next section we discuss how one might effectively manage to

515 prevent an impending regime shift.

AN ILLUSTRATIVE EXAMPLE: CAN PRO-ACTIVE MANAGEMENT AVOID A REGIME SHIFT?

Consider a situation where an oligotrophic lake is at equilibrium and is receiving only

519 non-point-source agricultural inputs of $\mathrm{P}$ that leach slowly from the soil (as in the starting 
R. Contamin \& A. M. Ellison - 25

521 with data from other oligotrophic and eutrophic lakes, we can be confident that the lake has some

522 lengthy but undetermined time to go before it crosses a threshold into a new nutrient regime. A

523 new use is proposed for the lake: an industrial plant wants to discharge $\mathrm{P}$ into the lake, and a

524 management plan is needed to allow increased inputs into the lake while avoiding an undesirable

525 regime shift. The site manager is able only to monitor the amount of $\mathrm{P}$ in the lake and the

526 agricultural (non-point-source) inputs of $\mathrm{P}$ into the lake, and to control only the proposed

527 industrial inputs into the lake. Our results from the analyses presented in the preceding sections

528 suggest the following simple management algorithm:

1. Allow linear increases in industrial inputs, calculate indicator values annually, and use the detection algorithm (Box 1) to detect when recycling of $\mathrm{P}$ from sediments into the water column begins.

2. Based on the input level when detection occurs, estimate the amount of total inputs (nonpoint-source + point-source) that will keep the lake far enough from the threshold so that a stochastic event (e.g., an unanticipated spike in P inputs) will not trigger a regime shift.

3. Increase or decrease allowable point-source inputs in line with measured agricultural

540 we first illustrate the effect of the time at which a regime shift is first detected on the risk of an

541 actual regime shift. Second, we examine the influence of changing model parameters on the risk

542 of triggering a regime shift. This sensitivity analysis allow us to determine the robustness of this

543 management algorithm to changes in parameters and therefore to identify how altering a 
R. Contamin \& A. M. Ellison - 26

544 management "strategy" (i.e., a set of adjustable parameters defined in the next paragraph) affects

545 the final outcome. We don't show the results for total inputs into the lake, but these are

546 correlated with the risk of regime shifts.

\section{Methods}

549 We ran 500-year simulations starting at oligotrophic equilibrium (initial $F_{a}=0.3 ; \varepsilon=$

$5500.01 ; \lambda=0.35$ ), only agricultural inputs, and a linear increase in $F_{a}$ that leads to a doubling of

551 non-point-source $\mathrm{P}$ inputs in 40 years. We ran 500 replicate simulations and noted the proportion

552 of replicates that led to a regime shift. We used the SPEC indicator, which had the best

553 performance in detecting regime shifts across a broad range of conditions (see Figs. 6-8), and

554 noted the percentage of regime shifts detected for each year prior to the regime shift.

555 For each set of simulations we defined two sets of parameters. System parameters are

556 parameters that a manager cannot control. These system parameters include the variance

557 parameters $\lambda$ and $\varepsilon$ and the non-point-source agricultural inputs $F_{a}$. Note that the initial value of

$558 \quad F_{a}$ defines the distance of the system from its threshold. Management parameters are parameters

559 that a manager can control. These management parameters are: (1) Speed, the rate at which total

560 inputs can increase, and here is referenced to the time needed to double the initial $\mathrm{P}$ inputs into

561 the system (the higher the value of Speed, the lower the increase in input rate of P); (2) the

562 detection factor FAC used to calibrate the indicator (Eqn. 9 in Box 1); and (3) the Best input,

563 which is the amount of allowable point-source $\mathrm{P}$ inputs set by the manager, relative to input

564 levels when the impending regime shift is detected. We call a given set of management

565 parameters a management strategy. Note that even though a manager cannot control the system 
R. Contamin \& A. M. Ellison - 27

566 parameters, knowledge of them can be used to alter management parameters and to improve the 567 management strategy.

570 When impending regime shifts were detected far in advance, the sensitivity of the

571 algorithm could be decreased by modifying the management parameters so as to reduce the time

572 from detection to potential regime shift $\left(\right.$ Year $\left._{D}\right)$ without increasing the risk of regime shift.

573 However, once $\operatorname{Year}_{D}$ declined to $\sim 60$ simulated years prior to a regime shift, the percent of 574 actual regime shifts that occurred began to increase exponentially (Fig. 9). By Year $_{D} \sim 30$, the 575 probability that a regime shift would occur approached 1 due to the inertia in the system.

Table 4 illustrates how changes in system parameters and management parameters altered

577 the probability of a regime shift. The probability of runs resulting in regime shifts ranged from

$578 \quad 1 \%$ to $69 \%$, with higher numbers resulting from high input levels or lower sensitivity of the

579 indicator. Increasing variability in the system (higher values of $\varepsilon$ or $\lambda$ ) decreased the sensitivity

580 of the indicator, made detection more difficult and led to higher probabilities of regime shifts.

581 Larger values of these parameters also increased the risk that stochastic events could trigger

582 regime shifts, even if they were detected well in advance. If a manager knows from past

583 observations that these system parameters are high, s/he can keep point-source inputs lower to

584 reduce the probability that a regime shift occurs (and reduce total inputs into the system). The

585 crucial result is that detection algorithms need sufficient data to provide adequate warning of an

586 impending regime shift: 20-30 simulated years seems to be the minimum we observed for any of

587 our indicators. 
R. Contamin \& A. M. Ellison - 28

591 (Equations 1-3) and generally unknown. Individual instances of the model reflect propagation of 592 stochastic process variance, and final outcomes can vary greatly (and thus we illustrate 593 probabilities of regime shifts over multiple runs in Figs. 5 and 9). Although we can simulate

594 multiple instances of the generating equations and analytically determine the consequences of the 595 propagation of process error through the model, managers and decision-makers are monitoring 596 only a single realization of this process. And it is to this single realization that the detection 597 algorithm (Box 1) would be applied. In different situations (or in different runs of the model), the 598 realization of the process will also differ, but the algorithm should still work effectively. This is 599 because managers are not trying to understand the underlying generating process itself, but rather 600 they are trying to detect and respond to patterns emerging from a particular instance.

601 Observation error does not propagate through time in the model, but it may have more 602 significant consequences in a management context because errors in observation may lead to 603 erroneous assessment of the probability of a regime shift. Our model (Eqns. 1-3) does not 604 incorporate observation error, but it is relatively straightforward to measure P content of water. 605 In general, monitoring programs should measure variables with sufficient precision and accuracy 606 so that the observation error is small, or at least is dominated by the process error. Regime shifts occur in a wide range of ecological systems, including forests (e.g.,

610 Lawrence et al. 2007, Millar et al. 2007, deYoung et al. 2008), fisheries and other large marine 611 ecosystems (e.g., Mantua 2004, Daskalov et al. 2007), and grasslands and rangelands (e.g., 
R. Contamin \& A. M. Ellison - 29

612 Anderies et al. 2002, Bestelmeyer 2006). A rapidly growing database of thresholds and regime

613 shifts in ecological systems is described by Walker and Meyers (2004) and is maintained online

614 by the Resilience Alliance. ${ }^{1}$ Conceptual reviews identify two broad categories of regime shifts -

615 ecosystems that cross thresholds because state variables have changed, or ecosystems that can

616 occupy alternative stable states due to shifts in underlying system parameters (Beisner et al.

617 2003, Scheffer and Carpenter 2003). Our methods and analysis were developed for an example

618 of the first type of regime shift, and should be generally applicable to systems of both types

619 where new regimes are maintained by changes in state variables or other system drivers, and

620 where alternative stable states characterized by fold bifurcations do not occur. However, there

621 are also many examples in which alternative stable states can exist for the same set of underlying

622 system parameters - systems in which fold bifurcations exist in phase-space (e.g., Petraitis and

623 Latham 1999, Scheffer and Carpenter 2003, van Nes and Scheffer 2007, Carpenter et al. 2008).

624 Recent work suggests that such fold bifurcations are preceded by rising variance and

625 spectral density increase (Carpenter et al. 2008), but the behavior of these indicators near critical

626 points is not as smooth as we have found here, and other indicators may not work at all in these

627 situations. In fact, how variance changes before, during, and after a regime shift is bound to

628 differ in different ecosystems. For example, Kleinen et al. (2003) found that the variance

629 spectrum shifted to lower frequencies and longer wavelengths near regime shifts in oceanic

630 thermohaline circulation. Although our results along with others (e.g., Kleinen et al. 2003,

631 Rodionov 2005c, Carpenter and Brock 2006) suggest that properties of the variance spectrum

632 can be useful as indicators of regime shifts, there is probably no one property that will work for

633 all systems. Rather, if the emergent process has high frequency (such as P recycling in lakes),

\footnotetext{
${ }^{1}<\mathrm{http}: / /$ www.resalliance.org/183.php $>$
} 
R. Contamin \& A. M. Ellison - 30

634 then looking for indicators in the high frequency bands of the variance spectrum is likely to be

635 fruitful. In contrast, if the emergent process has low frequency (such as in ocean circulation),

636 then looking for indicators in the low frequency bands of the variance spectrum is more

637 appropriate. Either way, a basic process model of how the system works is crucial. In the

638 absence of detailed process information, management intervention should not wait for definitive

639 proof of, or a single number that may presage, an impending regime shift. Rather, expeditious

640 invocation of the precautionary principle in managing ecosystems seems prudent.

641 Our analysis illustrates that prospective indicators of regime shifts exist, but that when

642 information about true processes driving the system are incomplete or when intensive

643 management actions cannot be implemented rapidly, many years of advance warning are

644 required to avert a regime shift. The lake model we used as our example is based on detailed,

645 long-term study by a large number of investigators; the model accurately accounts for the

646 processes causing regime shifts in north temperate lakes (Carpenter 2003, Carpenter and Brock

647 2006). However, most managers have neither the time nor the money to invest in decades of

648 study by large groups of investigators to create a detailed model of a particular system.

649 Encouragingly, our analysis shows that with only a basic understanding of a few core processes,

650 managers still can identify indicators of impending regime shifts in lakes based on identifying

651 feedbacks among system parameters that occur well before thresholds are crossed and regime

652 shifts occur.

653 For the lake model, the indicator based on increases in the spectral density of the time

654 series of P recycling is best at detecting impending regime shifts, but other indicators (Table 2)

655 may be more effective for different ecosystems. The detection algorithm (Box 1) suggests a

656 method to explore the effectiveness of the different algorithms, which in all cases should provide 
R. Contamin \& A. M. Ellison - 31

657 a high "signal" of feedbacks in the face of "noise" from other processes. But even if impending

658 thresholds can be detected, prevention of regime shifts depends on the inertia of the system and

659 the rapidity with which a manager can react and implement management actions. In our example

660 of managing P inputs into a lake, we achieved good results because the management intervention

661 could occur quickly (immediate adjustment in $F_{i}$ ). If the time to intervention increases, regime

662 shifts may not be preventable even if managers can reliably detect thresholds well in advance.

663 But even when inertial aspects of a system limit the ability to prevent a regime shift, it may still

664 be important to intervene to reduce the hysteresis of the system so that it can return to its initial

665 state more rapidly.

666 Another important consideration is the number of slow variables that interact to cause a

667 regime shift. Management is easiest when only one slow variable causes the regime shift and

668 when that variable can be controlled. But when several slow variables are involved, and some

669 cannot be controlled (e.g., $F_{a}$ in our example) management may be more difficult. In our

670 example, since the controllable slow variable $\left(F_{i}\right)$ and the uncontrollable slow variable $\left(F_{a}\right)$ had

671 additive effects, their sum could be controlled simply by manipulating $F_{i}$. In other cases, such as

672 when the slow variables are either non-interacting or interact in non-linear ways, such

673 compensatory interventions may not be possible or successful.

674 Our work also suggests several additional avenues for future research in this area.

675 Combining several indicators of regime shifts into a composite indicator may increase the signal-

676 to-noise ratio in the analysis, thereby increasing the probability of detecting a true regime shift

677 early and decreasing the probability of falsely detecting a regime shift. We also assessed only

678 single year-to-year changes in indicator values (Box 1), but algorithms that consider multiple

679 successive year-to-year changes may provide a mechanism for assessing the significance of 
R. Contamin \& A. M. Ellison - 32

680 observed changes in the system (Rodionov 2005b). Further assessment of the propagation of

681 process error and the impact of observation errors of different magnitudes in the model, the

682 application of the management algorithm, and in real situations would help to provide additional

683 bounds on our ability to detect and respond to regime shifts. Finally we considered only linear

684 increases in a single parameter that caused a regime shift, but in many cases multiple parameters

685 will change nonlinearly, especially in the cases of fold bifurcations discussed above (and by

686 Carpenter et al. 2008). Future work should also focus on identifying changes in indicators values

687 that are caused by changes in multiple parameters - ideally ones that can be monitored easily and 688 that are due to processes that may actually lead to regime shifts.

\section{ACKNOWLEDGMENTS}

We thank Steve Carpenter and Andy Solow for helpful discussions and answering

692 repeated questions about their models and algorithms. David Foster made the initial observation

693 that the original lake model considers only one kind of input and encouraged us to explore

694 alternative (point-source) inputs in our model and analysis. The Harvard Forest lab discussion

695 group gave us valuable feedback at various stages of this project. Brandon Bestelmeyer, Ben

696 Bolker, Steve Carpenter, Elizabeth Farnsworth, David Foster, Clarisse Hart, and Subject Matter

697 Editor Tom Hobbs provided incisive and valuable comments on the penultimate version of the

698 manuscript. Our work was supported by an internship award to RC from ENS-ULM, and by NSF

699 grant DEB 06-20443. This is a contribution of the Harvard Forest Long Term Ecological

$700 \quad$ Research Site. 
R. Contamin \& A. M. Ellison - 33

704 Anderies, J. M., M. A. Janssen, and B. H. Waker. 2002. Grazing management, resilience, and the 705 dynamics of a fire-driven rangeland system. Ecosystems 5:23-44.

706 Beisner, B. E., D. T. Haydon, and K. Cuddington. 2003. Alternative stable states in ecology. $707 \quad$ Frontiers in Ecology and the Environment 1:376-382.

708 Bennett, E. M., T. Reed-Andersen, J. N. Houser, J. R. Gabriel, and S. R. Carpenter. 1999. A 709 phosphorus budget for the Lake Mendota watershed. Ecosystems 2:69-75.

710 Bestelmeyer, B. T. 2006. Threshold concepts and their use in rangeland management and 711 restoration: the good, the bad, and the insidious. Restoration Ecology 14:325-329.

712 Bestelmeyer, B. T., J. E. Herrick, J. R. Brown, D. A. Trujillo, and K. M. Havstad. 2004. Land 713 management in the American southwest: a state-and-transition approach to ecosystem 714 complexity. Environmental Management 34:38-51.

715 Brock, W. A., and S. R. Carpenter. 2006. Variance as a leading indicator of regime shift in $716 \quad$ ecosystem services. Ecology and Society 11:9.

717 Carpenter S. R. 2003. Regime shifts in lake ecosystems: pattern and variation. Ecology Institute, 718 Oldendorf/Luhe, Germany.

719 Carpenter, S. R., and W. A. Brock. 2006. Rising variance: a leading indicator of ecological $720 \quad$ transition. Ecology Letters 9:311-318.

721 Carpenter, S. R., and K. L. Cottingham. 1997. Reslience and restoration of lakes. Conservation $722 \quad$ Ecology 1:2.

723 Carpenter, S. R., D. Ludwig, and W. A. Brock. 1999. Management of eutrophication for lakes 724 subject to potentially irreversible change. Ecological Applications 9:751-771. 
R. Contamin \& A. M. Ellison - 34

725 Carpenter, S. R., W. A. Brock, J. J. Cole, J. F. Kitchell, and M. L. Pace. 2008. Leading indicators 726 of trophic cascades. Ecology Letters 11:128-138.

727 Daskalov, G. M., A. N. Grishin, S. Rodionov, and V. Mihneva. 2007. Trophic cascades triggered 728 by overfishing reveal possible mechanisms of ecosystem regime shifts. Proceedings of

deYoung, B., M. Barange, G. Beaugrand, R. Harris, R. I. Perry, M. Scheffer, and F. Werner. 2008. Regime shifts in marine ecosystems: detection, prediction and management. Trends

Fath, B. D., H. Cabezas, and C. W. Pawloswki. 2003. Regime changes in ecological systems: an information theory approach. Journal of Theoretical Biology 222:517-530.

Gbondo-Tugbawa, S. S., C. T. Driscoll, M. J. Mitchell, J. D. Aber, and G. E. Likens. 2002. A model to simulate the response of a northern hardwood forest ecosystem to changes in $\mathrm{S}$ deposition. Ecological Applications 12:8-23.

Holland, E.A., B. H. Braswell, J Sulzman, and J.-F. Lamarque. 2005. Nitrogen deposition onto the United States and Western Europe: synthesis of observations and models. Ecological Applications 15:38-57.

Holling, C. S. 1973. Resilience and stability of ecological systems. Annual Review of Ecology and Systematics 4:1-23.

Keller, K., M. Hall, S. R. Kim, D. F. Bradford, and M. Oppenheimer. 2005. Avoiding dangerous anthropogenic interference with the climate system. Climatic Change 73:227-238. 
R. Contamin \& A. M. Ellison - 35

748 Kleinen, T., H. Held, and G. Petschel-Held. 2003. The potential role of spectral properties in

749 detecting thresholds in the earth system: application to the thermohaline circulation.

$750 \quad$ Ocean Dynamics 53:53-63.

751 Lawrence, D., P. D’Odorico, L. Diekmann, M. DeLonge, R. Das, and J. Eaton. 2007. Ecological

752 feedbacks following deforestation create the potential for a catastrophic ecosystem shift

753 in tropical dry forest. Proceedings of the National Academy of Sciences, USA

$754 \quad \mathbf{1 0 4}: 20696-20701$.

755 Lazante, J. R. 1996. Resistant, robust and non-parametric techniques for the analysis of climate

756 data: theory and examples, including applications to historical radiosonde station data.

757 International Journal of Climatology 16:1197-1226.

758 Litzow, M. A., and L. Ciannelli. 2007. Oscillating trophic control induces community

759 reorganization in a marine ecosystem. Ecology Letters 10:1124-1134.

760 Ludwig, D., W. A. Brock, and S. R. Carpenter. 2005. Uncertainty in discount models and

761 environmental accounting. Ecology and Society 10:article 13.

762 Ludwig, D., S. R. Carpenter, and W. A. Brock. 2003. Optimal phosphorus loading for a

763 potentially eutrophic lake. Ecological Applications 13:1135-1152.

764 Mantua, N. 2004. Methods for detecting regime shifts in large marine ecosystems: a review with 765 approaches applied to North Pacific data. Progress in Oceanography 60:165-182.

766 May, R. M. 1977. Thresholds and breakpoints in ecosystems with a multiplicity of stable states.

$767 \quad$ Nature 269:471-477.

768 Millar, C. I., N. L. Stephenson, and S. L. Stephens. 2007. Climate change and forests of the

769 future: managing in the face of uncertainty. Ecological Applications 17:2145-2151. 
R. Contamin \& A. M. Ellison - 36

770 Petraitis, P. S., and R. E. Latham. 1999. The importance of scale in testing the origins of

$771 \quad$ alternative community states. Ecology 80:429-442, 1999.

772 Pole A., M. West, and J. Harrison. 1994. Applied Bayesian forecasting and time series analysis.

773 Chapman \& Hall, New York, New York, USA.

774 R Development Core Team (2007). R: A language and environment for statistical computing. R

775 Foundation for Statistical Computing, Vienna, Austria. http://www.R-project.org.

776 Rabalais, N. N., R. E. Turner, and W. J. Wiseman, Jr. 2002. Gulf of Mexico hypoxia, a.k.a. "The

777 Dead Zone”. Annual Review of Ecology and Systematics 33:235-263.

778 Rodionov, S. N. 2005a. A brief overview of the regime shift detection methods. Pages 17-24 in

779 V. Velikova, and N. Chipev, editors. Large-scale disturbances (regime shifts) and

780 recovery in aquatic ecosystems: challenges for management toward sustainability.

781 UNESCO-ROSTE/BAS Workshop on Regime Shifts, Varna, Bulgaria.

782 Rodionov, S. N. 2005b. A seqential algorithm for testing climate regime shifts. Geophysical

783 Research Letters 31:1-4.

784 Rodionov, S. N. 2005c. Detecting regime shifts in the mean and variance: methods and specific 785 examples. Pages 68-72 in V. Velikova, and N. Chipev, editors. Large-scale disturbances

786 (regime shifts) and recovery in aquatic ecosystems: challenges for management toward 787 sustainability. UNESCO-ROSTE/BAS Workshop on Regime Shifts, Varna, Bulgaria.

788 Scheffer, M., and S. R. Carpenter. 2003. Catastrophic regime shifts in ecosystems: linking theory 789 to observation. Trends in Ecology and Evolution 18:648-656.

790 Schröder, A., L. Persson, and A. M. de Roos. 2005. Direct experimental evidence for alternative 791 stable states: a review. Oikos 110:3-19. 
R. Contamin \& A. M. Ellison - 37

792 Solow, A. R., and A. R. Beet. 2005. A test for a regime shift. Fisheries Oceanography 14:2362403.

794 Soranno, P. A., S. R. Carpenter, and R. C. Lathrop. 1997. Internal phosphorus loading in Lake 795 Mendota: response to external loads and weather. Canadian Journal of Fisheries and $796 \quad$ Aquatic Science 54:1883-1893.

797 Steele, J. H. 1998. Regime shifts in marine ecosystems. Ecological Applications 8 798 (Supplement):S33-S36.

799 Vanarsdale, A., J. Weiss, G. Keeler, E. Miller, G. Boulet, R. Brulotte, and L. Poissant. 2005.

$800 \quad$ Patterns of mercury deposition and concentration in northeastern North America (1996801 2002). Ecotoxicology 14:37-52.

802 van Nes, E. H., and M. Scheffer. 2007. Slow recovery from perturbations as a generic indicator 803 of a nearby catastrophic shift. American Naturalist 168:738-747.

804 Walker, B., and J. A. Meyers. 2004. Thresholds in ecological and social-ecological systems: a 805 developing database. Ecology and Society 9:3. 
806 Table 1 - Parameters used in the basic model (after Carpenter and Brock 2006, with addition of $F_{i}$ ).

\begin{tabular}{|c|c|c|c|c|}
\hline Symbol & Definition & Units & $\begin{array}{l}\text { Nominal } \\
\text { value }\end{array}$ & Source \\
\hline$b$ & Permanent burial rate of sediment $\mathrm{P}$ & $\mathrm{y}^{-1}$ & 0.001 & Carpenter (2003) \\
\hline C & Transfer coefficient of $\mathrm{P}$ from soil to lake & $\mathrm{y}^{-1}$ & 0.00115 & $\begin{array}{l}\text { Calculated from data of } \\
\text { Bennett et al. (1999) }\end{array}$ \\
\hline$F_{a}$ & $\begin{array}{l}\text { Net annual input of } \mathrm{P} \text { to the watershed soil per unit lake area } \\
\text { (weathering plus airborne input plus fertilizer application minus } \\
\text { removal of phosphorus in harvest) }\end{array}$ & $\mathrm{g} \mathrm{m}^{-2} \mathrm{y}^{-1}$ & Variable & $\begin{array}{l}\text { Bennett et al. (1999) } \\
\text { estimated } F_{a}=14.6\end{array}$ \\
\hline$F_{i}$ & Net annual point-source input of $P$ to the water per unit lake & $\mathrm{g} \mathrm{m}^{-2} \mathrm{y}^{-1}$ & Variable & \\
\hline$h$ & Outflow rate of $\mathrm{P}$ & $\mathrm{y}^{-1}$ & 0.15 & Carpenter (2003) \\
\hline$H$ & Annual variance in input of $\mathrm{P}$ from soil into water & unitless & $f(\lambda)$ & \\
\hline$m$ & $\begin{array}{l}\text { P density in the lake when recycling is half its maximum possible } \\
(R(m)=0.5)\end{array}$ & $\mathrm{g} \mathrm{m}^{-2}$ & 2.4 & Carpenter (2003) \\
\hline$M$ & Concentration of $\mathrm{P}$ in lake sediments & $\mathrm{g} \mathrm{m}^{-2}$ & Variable & \\
\hline
\end{tabular}


R. Contamin \& A. M. Ellison - 39

\begin{tabular}{|c|c|c|c|c|}
\hline$q$ & Parameter for steepness of $R(X)$ near $m$ & unitless & 8 & Carpenter (2003) \\
\hline$r$ & $\begin{array}{l}\text { Recycling coefficient of } \mathrm{P} \text { from sediment to lake (= maximum } \\
\text { recycling rate of } \mathrm{P}\end{array}$ & $\mathrm{g} \mathrm{m}^{-2} \mathrm{y}^{-1}$ & 0.019 & Carpenter (2003) \\
\hline$R(X)$ & Recycling function (see Eqn. 4) & unitless & $f(X, m, q)$ & \\
\hline$S$ & Sedimentation rate of $\mathrm{P}$ & $\mathrm{g} \mathrm{m}^{-2} \mathrm{y}^{-1}$ & 0.7 & Carpenter (2003) \\
\hline$U$ & Concentration of $\mathrm{P}$ in soil & $\mathrm{g} \mathrm{m}^{-2}$ & Variable & \\
\hline$X$ & Concentration of $\mathrm{P}$ in lake & $\mathrm{g} \mathrm{m}^{-2}$ & Variable & \\
\hline$\lambda$ & Standard deviation of annual P input & unitless & 0.35 & Carpenter (2003) \\
\hline$\varepsilon$ & Control parameter on within-year variance in $\mathrm{P}$ input & unitless & 0.01 & Carpenter (2003) \\
\hline$\sigma$ & Control parameter on recycling of $\mathrm{P}$ during the summer & unitless & 0.01 & Carpenter (2003) \\
\hline
\end{tabular}


R. Contamin \& A. M. Ellison - 40

807 Table 2. Six indicators of regime shifts. In each of these equations, $\mathbf{X}$ is the vector of 36

808 observed within-year values (indexed by $k$ ) of the concentration of $\mathrm{P}$ in the water column in year

$809 t$.

810

\begin{tabular}{|c|c|c|}
\hline Type of indicator & Name of indicator & Equation \\
\hline \multirow{3}{*}{ Variance indicator } & SD & $S D_{t}=\sqrt{\sum_{k=1}^{36} \frac{\left(X_{t, k}-\overline{\mathbf{X}_{t}}\right)^{2}}{36}}$ \\
\hline & SD $_{\text {DLM }}$ & $S D_{[\mathrm{DLM}] t}=\sqrt{\sum_{k=1}^{36} \frac{\left(X_{t, k}-\overline{\mathbf{X}_{[\mathrm{DLM}] t}}\right)^{2}}{36}}$ \\
\hline & SD $_{\text {rec }}$ & $S D_{[\mathrm{rec}], t}=\sqrt{\sum_{k=1}^{36} \frac{\left(X_{t, k}-\overline{\mathbf{X}_{[\mathrm{rec}](\mathrm{t}), k}}\right)^{2}}{36}}$ \\
\hline Spectrum indicator & SPEC & $\operatorname{Spec}_{t}=\max \left(\operatorname{spec}\left(X_{t, k \in 1: 36}\right)\right)$ \\
\hline DLM indicator & $A_{0}$ & Upgraded parameter $a_{0}$ (from Eqns 6,7 ) \\
\hline "Control” & $\boldsymbol{X}$ & $X=\overline{\mathbf{X}_{t}}$ \\
\hline
\end{tabular}


R. Contamin \& A. M. Ellison - 41

812 Table 3. Values of the three variance parameters used in the simulations to determine the power 813 of each indicator listed in Table 1.

814

\begin{tabular}{lccc}
\hline \hline Set number & $\lambda$ & $\varepsilon$ & $\sigma$ \\
\hline 1 & 0.01 & 0.001 & 0 \\
2 & 0.01 & 0.001 & 0.01 \\
3 & 0.01 & 0.01 & 0.01 \\
4 & 0.10 & 0.001 & 0.01 \\
5 & 0.35 & 0.001 & 0.01 \\
6 & 0.35 & 0.01 & 0.01 \\
\hline
\end{tabular}


815 Table 4. Results of the sensitivity analysis of varying system and management parameters on the probability that regime shifts occur.

816 Values shown are means of 500 simulations for each set of parameters. The SPEC indicator was used to detect impending regime

817 shifts. The percent of regime shifts that occurred in the model are those that occurred after simulated management intervention was

818 applied as described in text.

819

\begin{tabular}{|c|c|c|c|c|}
\hline \multirow{3}{*}{ Fixed parameters } & \multicolumn{4}{|c|}{ Percent of } \\
\hline & \multicolumn{2}{|c|}{ Variable parameters } & & \multirow[t]{2}{*}{ Conclusion } \\
\hline & Relative & Absolute & & \\
\hline & Low & $\lambda=0.1 ; \varepsilon=0.001 ; \sigma=0.01$ & 1.2 & Regime shifts are more \\
\hline \multicolumn{5}{|l|}{ Initial $F_{a}=0.3$} \\
\hline \multicolumn{5}{|l|}{ Speed $=40$} \\
\hline & & & & occur more frequently as \\
\hline \multicolumn{5}{|l|}{$\mathrm{FAC}=10$} \\
\hline Best Input $=0.9$ & High & $\lambda=0.5 ; \varepsilon=0.02 ; \sigma=0.01$ & 53 & $\begin{array}{l}\text { variability in the system } \\
\text { increases. }\end{array}$ \\
\hline
\end{tabular}

$\begin{array}{lll}\lambda=0.35 ; \varepsilon=0.01 ; \sigma=0.01 & \text { Low } & \text { Initial } F_{a}=0.2 \\ & \text { Medium } & \text { Initial } F_{a}=0.3\end{array}$

10 The closer one is initially

23 to the threshold, the harder 
R. Contamin \& A. M. Ellison - 43

Speed $=40$

$\mathrm{FAC}=10$

Best Input $=0.9$
High Initial $F_{a}=0.4$

Medium $\quad$ Speed $=40$

$\lambda=0.35 ; \varepsilon=0.01 ; \sigma=0.01$

Initial $F_{a}=0.3$

$\mathrm{FAC}=10$

Best Input $=0.9$

High $\quad$ Speed $=60$

it will be for the indicator

to detect the regime shift

36

with ample warning (see

Fig. 2)

35 Allowing for a more rapid

19 rate of new inputs gives

less time for the indicator

to detect the regime shift

18 before it happens. Thus,

the percent of regime

shifts increases.

$\begin{array}{lll}\lambda=0.35 ; \varepsilon=0.01 ; \sigma=0.01 & \text { Low } & \text { FAC }=5 \\ & \text { Medium } & \text { FAC }=10\end{array}$

1.2 As the tuning coefficient

19 increases, the detection 
R. Contamin \& A. M. Ellison - 44

Initial $F_{a}=0.3$

Speed $=40$

Best Input $=0.9$
High

$$
\mathrm{FAC}=20
$$

Low

Best Input $=0.75$

Medium
Best Input $=0.9$ rate declines and the

67 probability of regime shift

increases

2 Higher allowable inputs is

18 a special paramter It has 
R. Contamin \& A. M. Ellison - 45

Initial $F_{a}=0.3$

Speed $=40$

$\mathrm{FAC}=10$ no effect on detection

time, but it is critical

because a high value

means that management

maintains the system close

to its threshold.

69 Consequently, after

detecting the potential

occurrence of a regime

shift, there is an increased

risk of a shift occurring

due to small disruptive

events. 
R. Contamin \& A. M. Ellison - 46

FigURE LEGENDS

821

822 Figure 1. Schematic drawing of the basic model of a lake ecosystem (after Carpenter and Brock 2006), with additional point-source inputs of $P$ ("Point-source P from industry"). Variables in parentheses correspond to variables in the model (Equations 1-3; Table 1).

Figure 2. Example of the behavior of the model (using basic parameter set described in Table 1)

87
subject to realistic increases in point-source or non-point source inputs. A - simulated point-source ( $F_{i}$ in Eqn. 2) or non-point-source ( $F_{a}$ in Eqn. 1) inputs of phosphorus. B total inputs $\left(F_{\text {total }}=F_{a}+F_{i}\right)$ following increases in point-source inputs only. $\mathbf{C}$ - total inputs $\left(F_{\text {total }}=F_{a}+F_{i}\right)$ following increases in non-point-source inputs only. $\mathbf{D}$ - total $\mathbf{P}$ in water column when point-source inputs are increased and then eliminated. $\mathbf{E}$ - total P in water column when non-point-source inputs are increased and then eliminated. In B, C,

Figure 3. Effects of the three variance parameters $(\lambda, \varepsilon$, and $\sigma)$ on time-series of concentration of $\mathbf{D}$, and $\mathbf{E}$, the light-grey vertical line indicates the onset of observable recycling of $\mathrm{P}$ from lake sediments into the water column $(R(X)=0.0001)$, and the dark-grey vertical line indicates the shift from an oligotrophic to a eutrophic regime. $\mathrm{P}$ in the water column and its standard deviation. $\mathbf{A}$ - The parameter $\lambda$ (here, $\lambda=0.35$ ) controls annual variability in concentration of $\mathrm{P}$ in the water. $\mathbf{B}$ - The standard deviation in annual concentration of $\mathrm{P}$ in the water increases along with inputs of $\mathrm{P}$ from the soil $\left(F_{\text {soil }}\right)$. C - The parameter $\varepsilon$ controls within-year variability in concentration of $\mathrm{P}$ in the water (here, $\varepsilon=0.01$ ). Note that in $\mathbf{A}, \mathbf{B}$, and $\mathbf{C}$ the $x$-axis (years) only ranges from 1-6 
R. Contamin \& A. M. Ellison - 47

years as these figures simply illustrate the type of variability controlled by each of the three parameters. $\mathbf{D}$ - The within-year standard deviation of concentration of $\mathrm{P}$ in the water increases with inputs of $\mathrm{P}$ from soil $\left(F_{\text {soil }}\right)$. $\mathbf{E}$ - The parameter $\sigma$ controls summer variability in recycling of $\mathrm{P}$ from lake sediments into the water column (here, $\sigma=0.01$ ). F - The standard deviation in concentration of $\mathrm{P}$ in the water column increases only after recycling of $\mathrm{P}$ from sediments into the water column reaches measurable levels $(R(X)=$ 0.0001; grey vertical line). For each of these runs, we used the base parameter values (Table 1). The only inputs of $\mathrm{P}$ to the system were from soil, and these inputs increased linearly through time (as in Fig. 2A up to simulated year 300).

Figure 4. Time series of concentration of $\mathrm{P}$ in the water column (top row) and the five indicators of regime shift (listed in Table 2) when the model was run only with noise due to recycling of $\mathrm{P}$ from sediment to the water column $(\sigma=0.01, \lambda=\varepsilon=0.0$; left column $)$ or when the model was run with all sources of variability included $(\sigma=0.01, \varepsilon=0.01, \lambda=$ 0.35; right column). The grey vertical line indicates when recycling of $\mathrm{P}$ from sediments into the water column reaches measurable levels $(R(X)=0.0001)$. In all runs, the system shifted from oligotrophic to eutrophic regimes at $\sim$ simulated year 250 . When all sources of variation were included in the model (right column), the "signal-to-noise" ratio was large from the time that recycling of $\mathrm{P}$ begins, $>100$ years before a regime shift. The "signal-to-noise" ratio is clearest for the SPEC indicator, which reliably signaled a regime shift $\sim 40$ years in advance. 
R. Contamin \& A. M. Ellison - 48

865 Figure 5. Probability of a regime shift (top row) and average time to recovery $(N=200$

simulation runs) from a eutrophic back to an oligotrophic regime (bottom row) as a function of time of three different management interventions when $\mathrm{P}$ inputs are due only to point-sources (left) or non-point-sources (right). Model parameters and input schedules as in Fig. 2. The three management interventions are slow (solid black line: 10 years from observable signal to response with a 50\% reduction in $\mathrm{P}$ achieved after 50 years); intermediate (dashed black line: 5 years from observable signal to response with a $90 \%$ reduction in $\mathrm{P}$ achieved after 10 years); and rapid (dashed-dotted black line: immediate

Figure 6. Power of each of the six indicators given in Table 2 as a function of time of management intervention (Delay) when all sources of noise are present in the model system (parameter set 6 of Table 3).

Figure 7. Total power of each of the six indicators given in Table 2 for all the parameter sets given in Table 3. Power of each indicator for each parameter set is calculated as the area under the Power vs. Delay curve (as illustrated in Fig. 6).

Figure 8. Error values (from Eqn. 10) for each of the six indicators given in Table 2 when all sources of variability were present in the model system (parameter set 6 of Table 3 ) and 
R. Contamin \& A. M. Ellison - 49

891

892 Figure 9. Probability that a regime shift occurs as a function of when it was detected. In the

for the optimal level of FAC for each indicator. A - model run with only non-point-source inputs ( $F_{a}$ increasing linearly, $F_{i}=0$, as in Fig. $2 \mathrm{D}$,). $\mathbf{B}-$ model run with only pointsource inputs increasing $\left(F_{a}=0.3 ; F_{i}\right.$ increasing linearly as in Fig. 2C). simulations used to generate these values, the system parameters were set at $\lambda=0.35, \varepsilon=$ $0.01, \sigma=0.01$, and initial $F_{a}=0.3$. Point-source inputs $\left(F_{i}\right)$ were allowed to increase linearly according to the management parameters Speed $=40$ years to doubling total inputs $\left(F_{\text {total }}=F_{i}+F_{a}\right)$ with the amount of allowable point-source inputs after management intervention Best inputs $=0.9$. The tuning coefficient for the detection indicator FAC was set equal to 10. This parameter set was the "medium" parameter set of Table 4. 


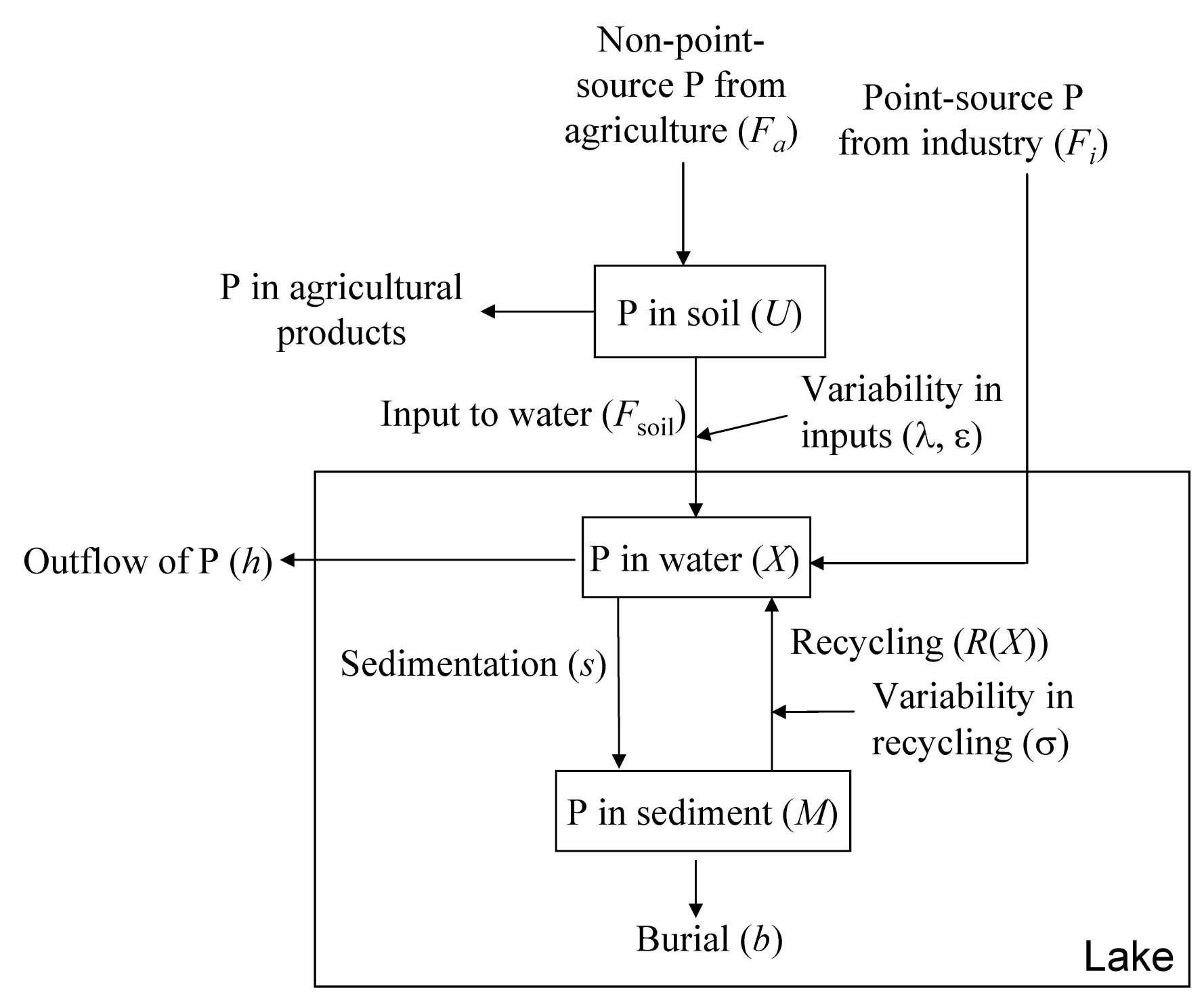



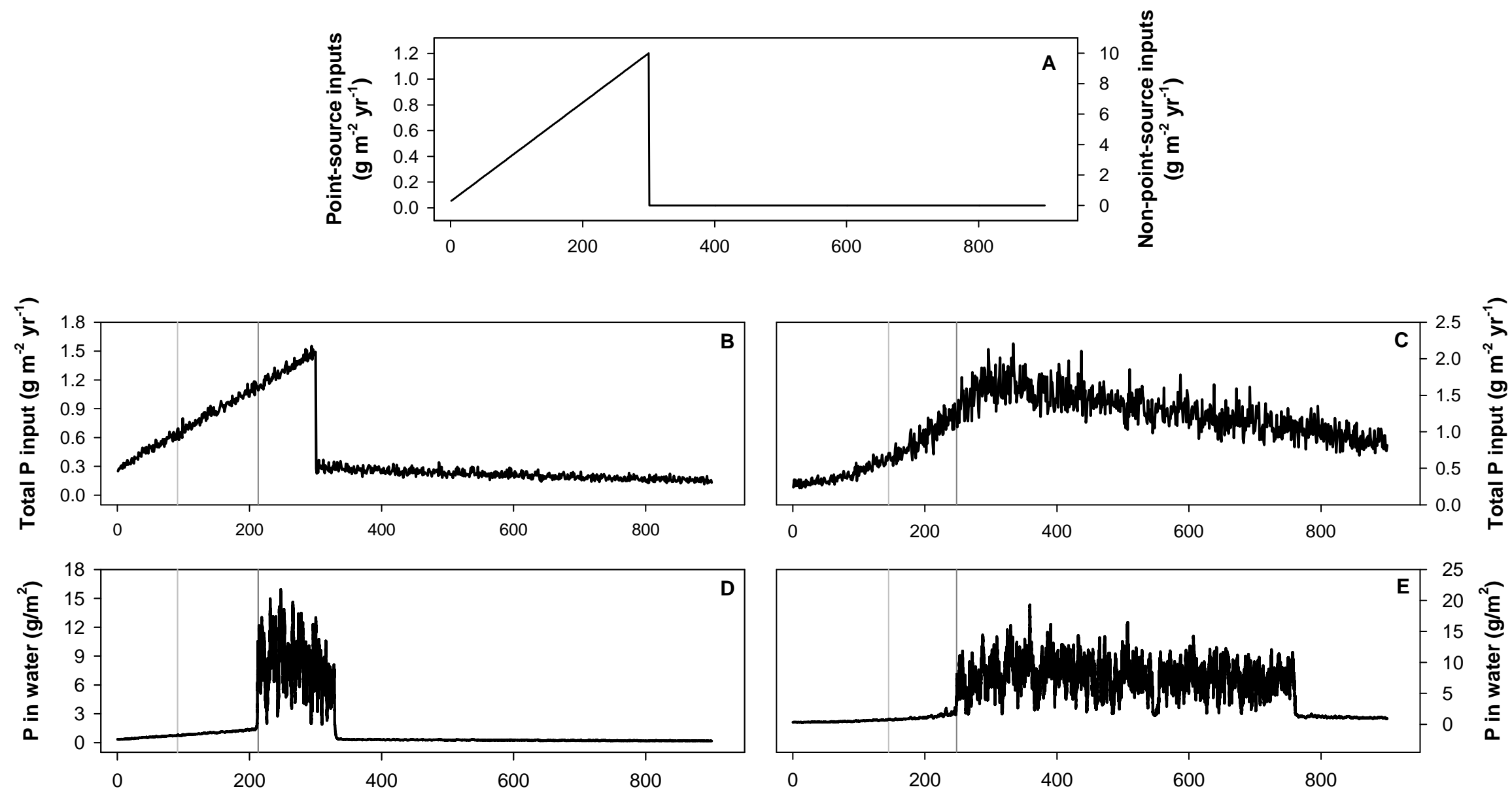

Time (simulated years) 

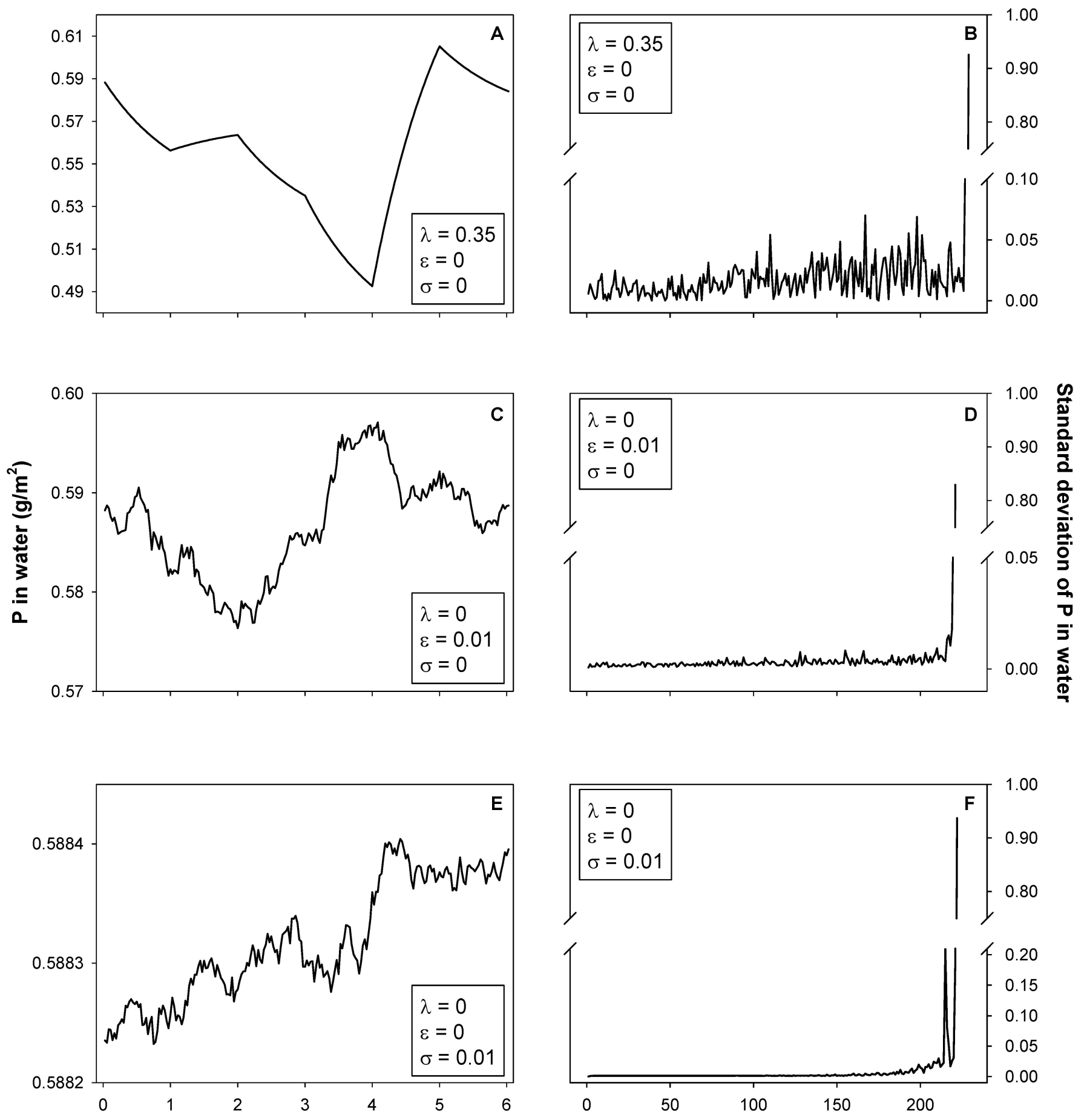

Time (simulated years) 

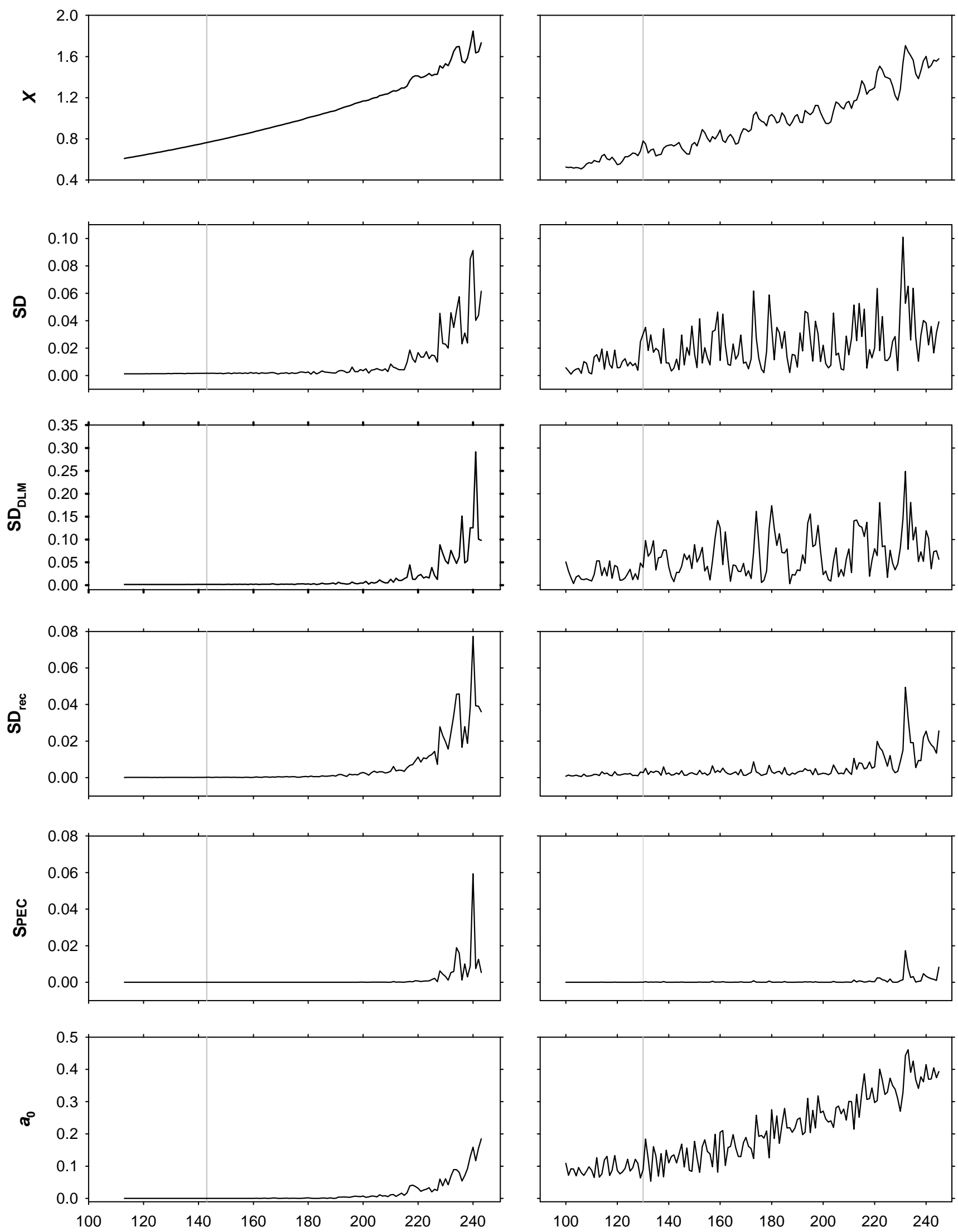

Time (simulated years) 
Only point-source input
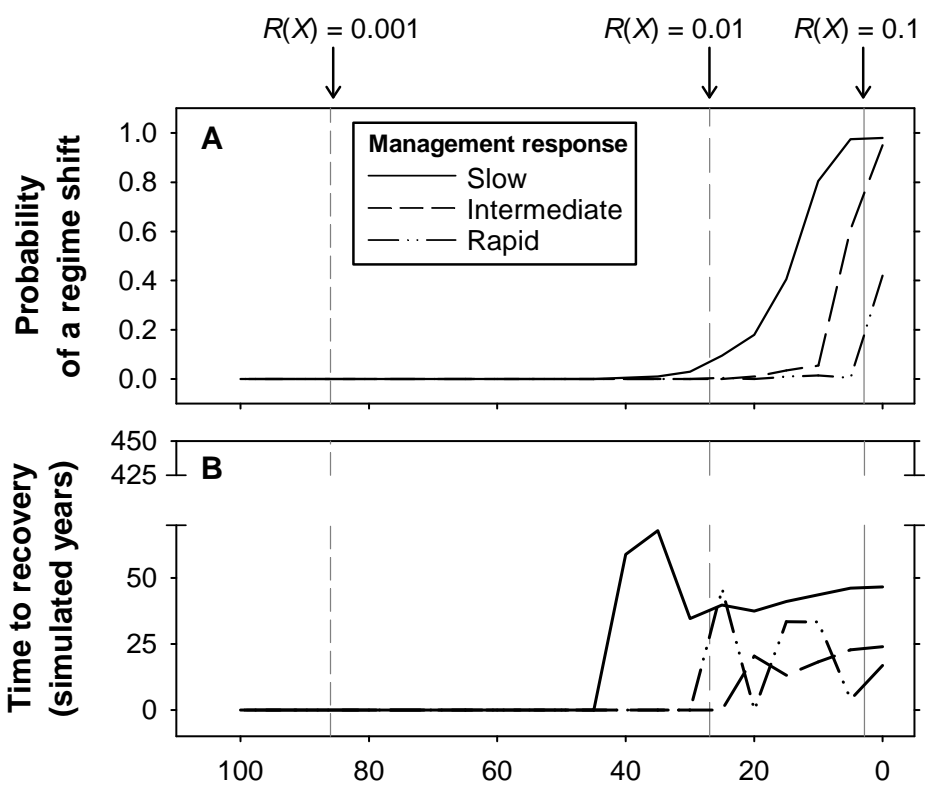

Only non-point source input
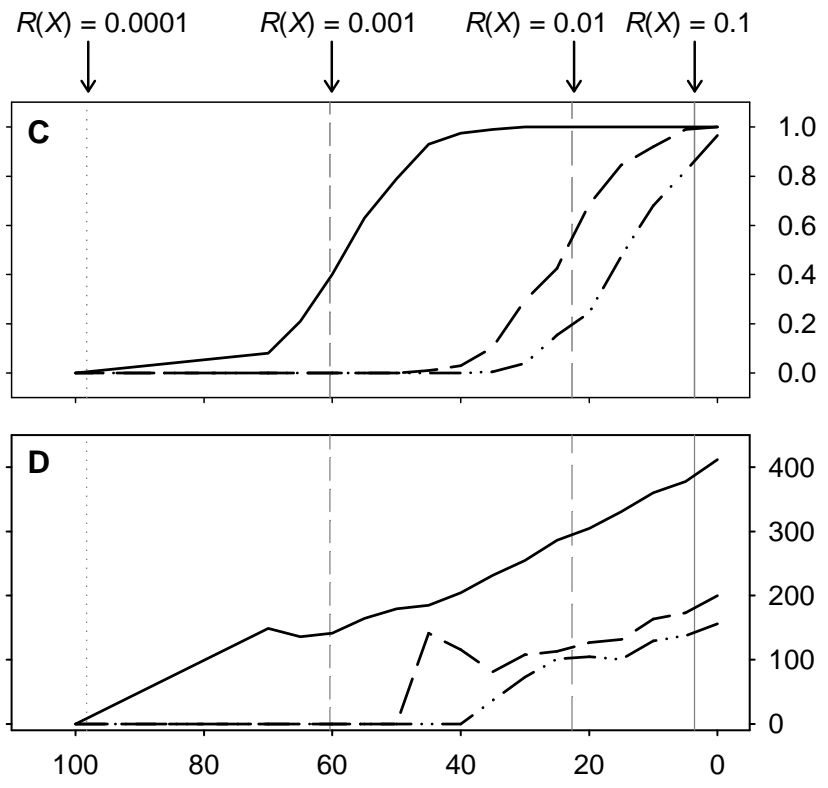

Time of management intervention (simulated years before present) 


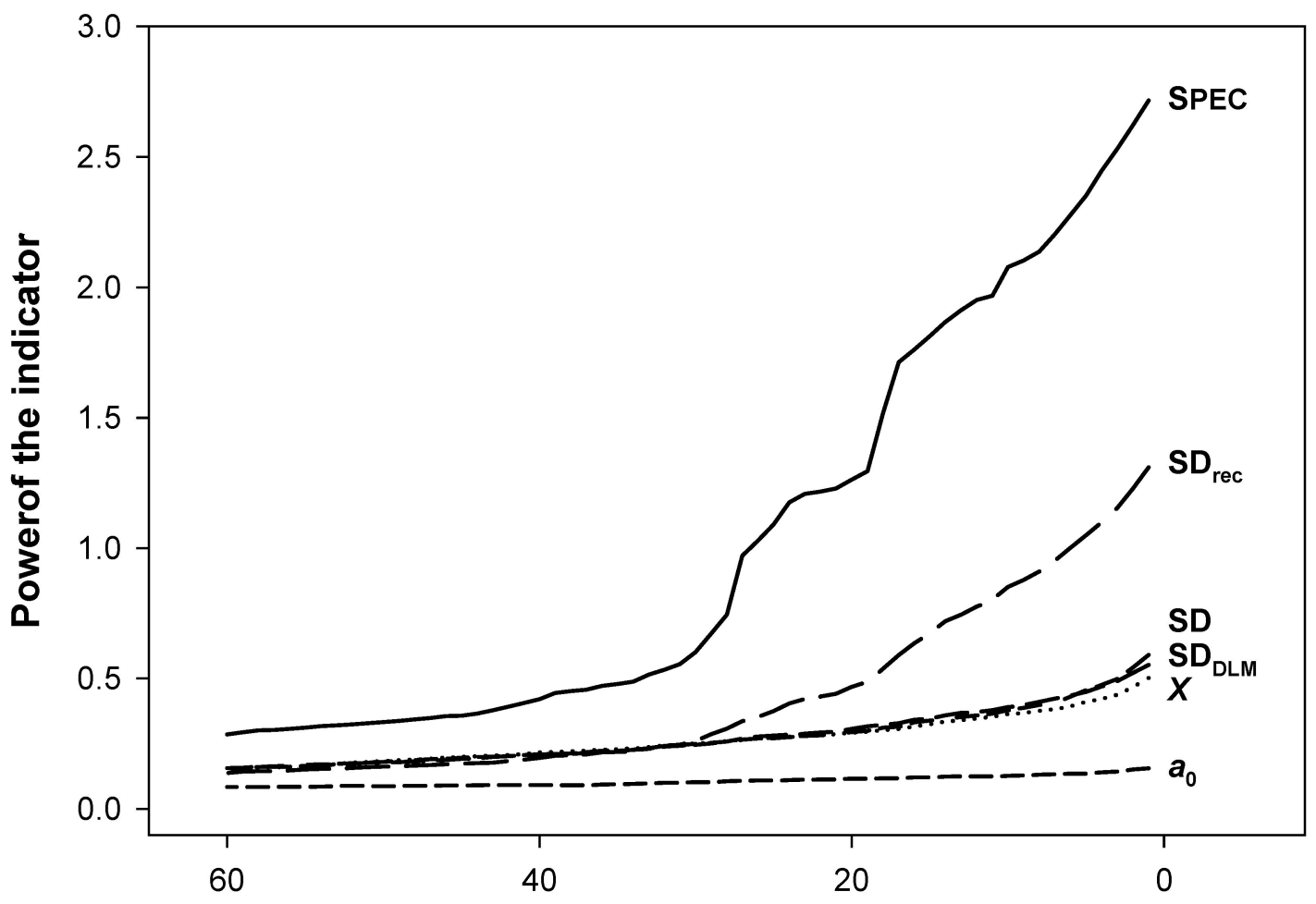

Time of management intervention (simulated years before regime shift) 


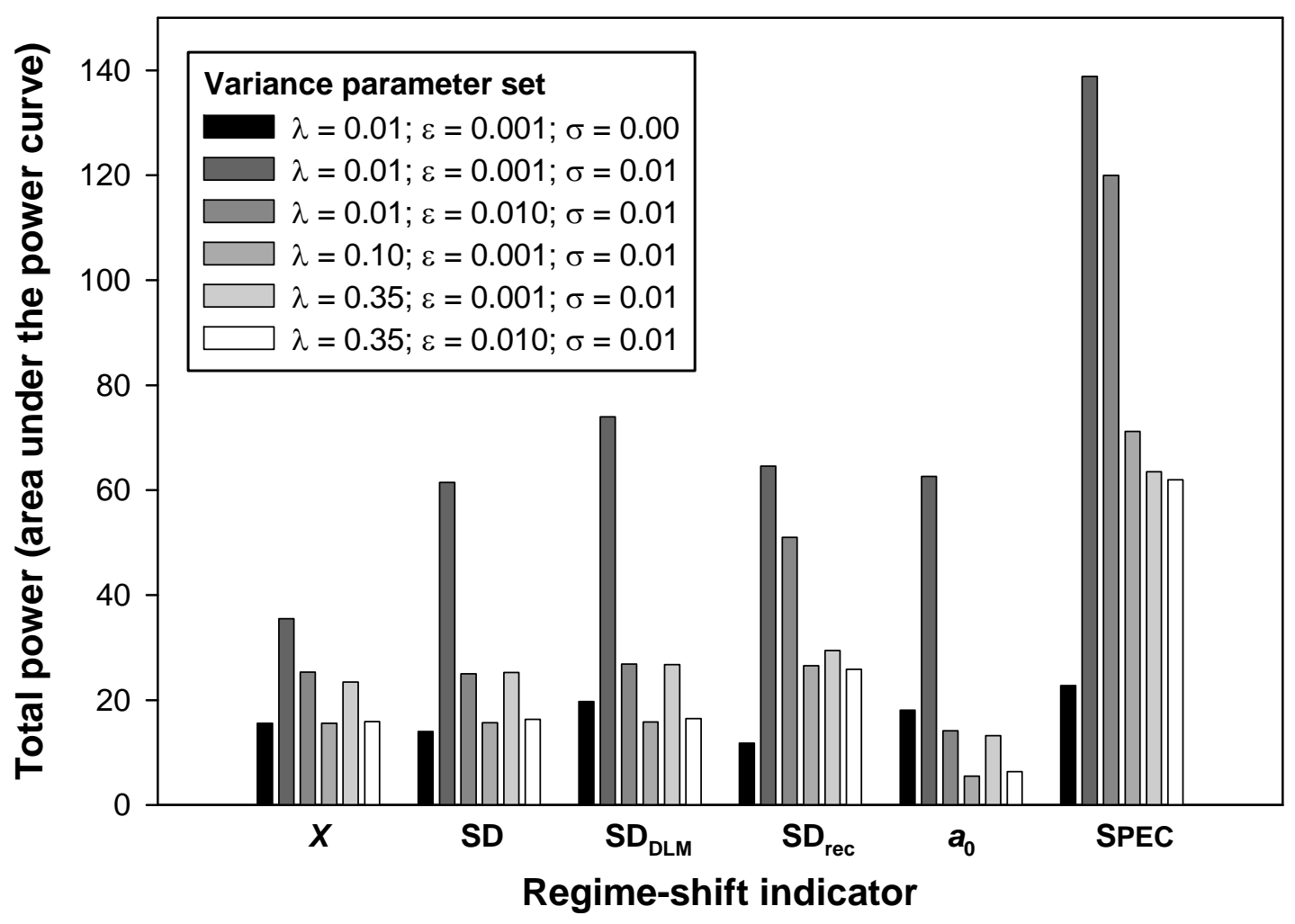




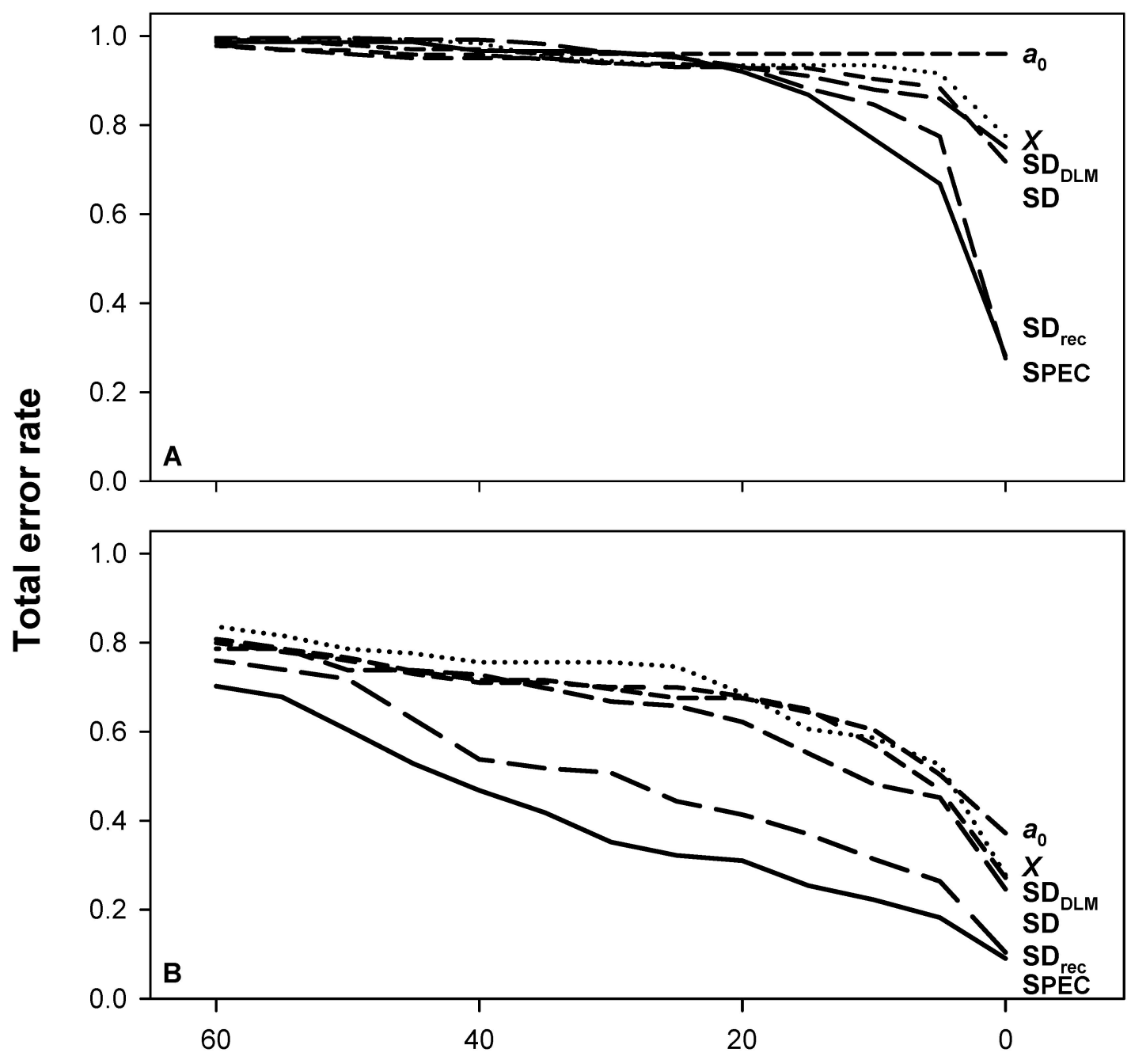

Time of management intervention (simulated years before regime shift) 


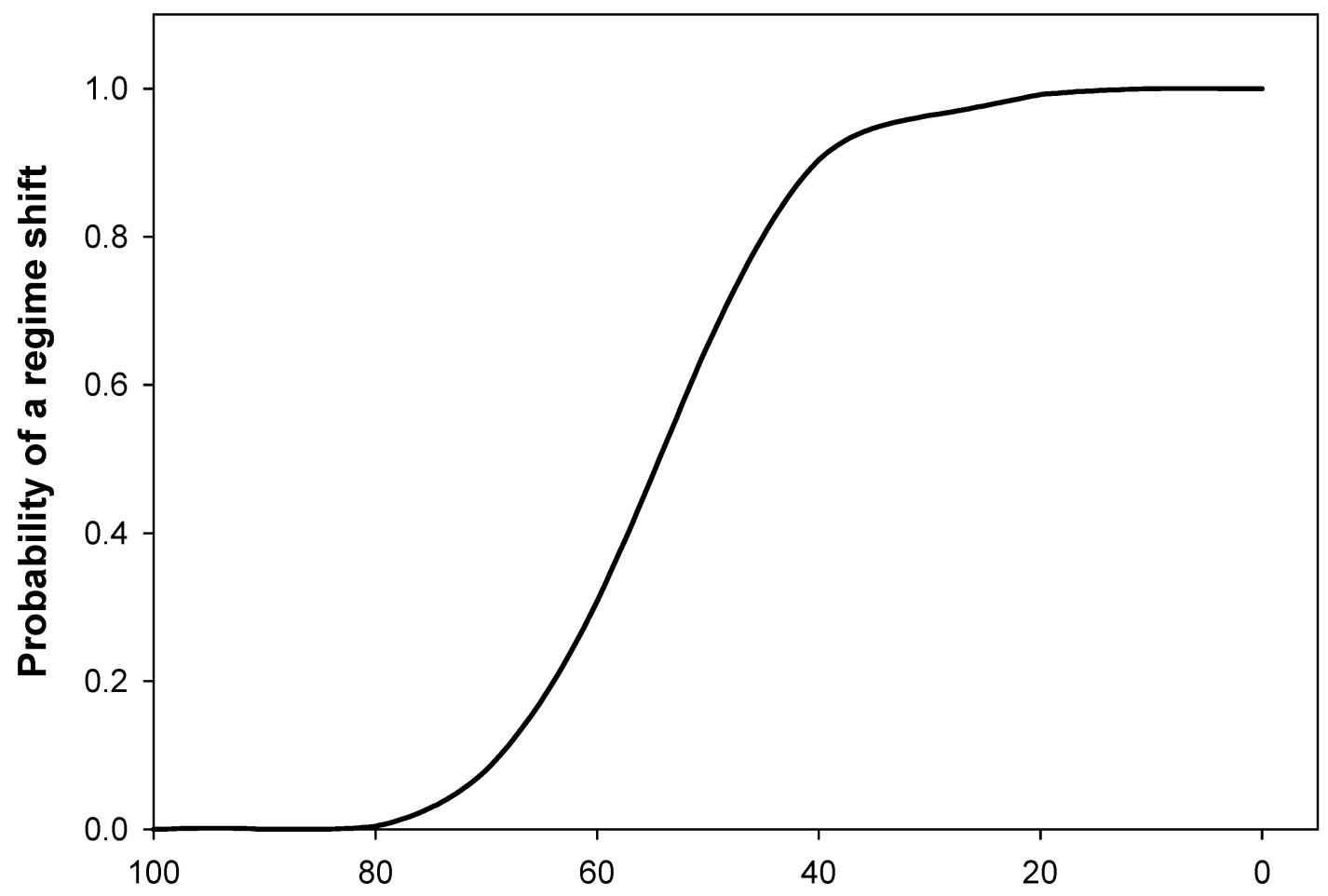

Time of detection (simulated years before the regime shift) 